\title{
¿Generation Mechanisms of Mesoscale Eddies in the Mauritanian Upwelling Region
}

\author{
Ahmad Fehmi Dilmahamod, ${ }^{\mathrm{a}, \mathrm{b}}$ Johannes Karstensen, ${ }^{\mathrm{a}}$ Heiner Dietze, ${ }^{\mathrm{c}}$ UlRiKe LÖPtien, ${ }^{\mathrm{c}}$ \\ AND KATJA FENNEL ${ }^{\text {b }}$

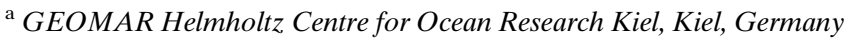 \\ ${ }^{\mathrm{b}}$ Department of Oceanography, Dalhousie University, Halifax, Nova Scotia, Canada \\ ${ }^{\mathrm{c}}$ Institut für Geowissenschaften, Christian-Albrechts-Universität zu Kiel, Kiel, Germany
}

(Manuscript received 22 April 2021, in final form 11 August 2021)

\begin{abstract}
The physical processes driving the genesis of surface- and subsurface-intensified cyclonic and anticyclonic eddies originating from the coastal current system of the Mauritanian upwelling region are investigated using a high-resolution $(\sim 1.5 \mathrm{~km})$ configuration of GFDL's Modular Ocean Model. Estimating an energy budget for the boundary current reveals a baroclinically unstable state during its intensification phase in boreal summer and which is driving eddy generation within the near-coastal region. The mean poleward coastal flow's interaction with the sloping topography induces enhanced anticyclonic vorticity, with potential vorticity close to zero generated in the bottom boundary layer. Flow separation at sharp topographic bends intensifies the anticyclonic vorticity, and submesoscale structures of low PV coalesce to form anticyclonic vortices. A combination of offshore Ekman transport and horizontal advection determined the amount of South Atlantic Central Water (SACW) in an anticyclonic eddy. A vortex with a relatively dense and low PV core will form an anticyclonic mode water eddy, which will subduct along isopycnals while propagating offshore and hence be shielded from surface buoyancy forcing. Less contribution of dense SACW promotes the generation of surface anticyclonic eddies as the core is composed of a lighter water mass, which causes the eddy to stay closer to the surface and hence be exposed to surface buoyancy forcing. Simulated cyclonic eddies are formed between the rotational flow of an offshore anticyclonic vortex and a poleward flowing boundary current, with eddy potential energy being the dominant source of eddy kinetic energy. All three types of eddies play a key role in the exchange between the Mauritanian coastal currents system and the adjacent eastern boundary shadow zone region.
\end{abstract}

KEYWORDS: Boundary currents; Eddies; Instability; Upwelling/downwelling

\section{Introduction}

Oceanic eddies at scales of $10-100 \mathrm{~km}$ are ubiquitous in the ocean (Chelton et al. 2007). The common paradigm of these features is that they are either cyclonic (CE) or anticyclonic (ACE), their vertical structures' characteristic of the first baroclinic mode (McWilliams and Flierl 1976; Wunsch 1997), where the main thermocline is heaved or depressed, respectively. Additionally, subsurface eddies are not uncommon and are mostly anticyclonic (McCoy et al. 2020), with the characteristic of a second baroclinic mode, manifested in a doming and bowling of isopycnal layers around a weakly stratified core (McWilliams 1985). These subsurface eddies exist in all oceans, e.g., in the tropical North Atlantic Ocean (Hebert et al. 1990; Carton et al. 2010; Bashmachnikov et al. 2015) or the south Indian Ocean (Nauw et al. 2006; Dilmahamod et al. 2018), but most extensively in eastern boundary upwelling systems (EBUSs; Frenger et al. 2018) such as in the South and North Pacific (Chaigneau et al. 2011; Pelland et al. 2013; Thomsen et al. 2016) and North Atlantic (Barceló-Llull et al. 2017; Karstensen et al. 2015; Schütte et al. 2016a). Nonlinear

¿Denotes content that is immediately available upon publication as open access.

Corresponding author: Ahmad Fehmi Dilmahamod, fehmi. dilmahamod@gmail.com eddies can trap water masses and transport them with surprisingly little modification over vast distances (Karstensen et al. 2015; Karstensen et al. 2017; Zhang et al. 2014). Eddies are known to impact the horizontal and vertical distribution of physical and biogeochemical tracers (McGillicuddy et al. 2007; Chelton et al. 2011b; Dong et al. 2014; Amos et al. 2019).

In certain regions, the eddy confined transport is of similar order of magnitude as that of the large-scale wind- and thermohaline-driven circulation (Zhang et al. 2014), especially in EBUSs that are characterized by a rather weak mean circulation. For the southeast Pacific Ocean, both cyclonic and anticyclonic vortices have been found to trap and transport coastal waters offshore into the subtropical gyre (Chaigneau et al. 2011; Holte et al. 2013). For the northeast Atlantic, studies showed that eddies contribute much to the along-isopycnal stirring of tracers (Brandt et al. 2015; Hahn et al. 2014; Stramma et al. 2010). Also, they have been found to induce a reduction of net primary productivity (NPP) in EBUSs by subducting nutrients along isopycnal surfaces that eventually plunge below the euphotic layer toward the open ocean (Gruber et al. 2011; Renault et al. 2016). Second or even higher vertical mode eddies have the ability to transport subsurface anomalies. Since the anomalies are largely shielded from surface buoyancy forcing, they gradually get more extreme with increasing distance from their formation region. Prominent examples of second- and higher-order vertical mode eddies are "Meddies," "Cuddies," and "Puddies," which 
originate from the Mediterranean outflow in the North Atlantic (Armi and Zenk 1984), from the California Undercurrent in the North Pacific (Garfield et al. 1999), and the Peru-Chile Undercurrent in the South Pacific (Hormazabal et al. 2013), respectively. For all the regions, the westward transport of heat, salt, oxygen, or nutrients anomalies have been reported (Combes et al. 2013; Frenger et al. 2018; Hormazabal et al. 2013; Lukas and Santiago-Mandujano 2001). The local submesoscale dynamics associated with mesoscale eddies (e.g., Lévy et al. 2012) can be a driver of local extremes that are not traceable to regional or large-scale tracer cycling (Altabet et al. 2012; ArévaloMartínez et al. 2016; Christiansen et al. 2018; Ellwood et al. 2020; Grundle et al. 2017; Karstensen et al. 2015, 2017; Löscher et al. 2015), emphasizing the need for a correct representation of eddy generation and eddy dynamics in ocean modeling (e.g., Uchida et al. 2020).

In EBUSs, the prevailing physical mechanisms are that oceanic eddies are formed through the instabilities of the mean flow (Liang et al. 2012; Pantoja et al. 2012), with the transfer of mean kinetic to eddy kinetic energy (horizontal Reynolds stress; barotropic instability) and available potential to eddy kinetic energy (vertical fluxes of buoyancy; baroclinic instability). This transfer of energy can be mainly triggered by wind perturbations (Pares-Sierra et al. 1993), large-scale circulation, and interactions with bottom topography (McWilliams 1985; D'Asaro 1988; Kurian et al. 2011) or poleward-propagating coastal trapped waves (Zamudio et al. 2007). Apart from baroclinic/barotropic instabilities, the interaction of the boundary current system with sharp topographic bends is also a customary feature involved in subsurface eddy generation (Gula et al. 2015; Molemaker et al. 2015; Thomsen et al. 2016; Contreras et al. 2019). Off the coasts of California and Peru, the generation processes of subsurface eddies have been associated with the mean flow (California Undercurrent and Peru-Chile Undercurrent) separation owing to the topographic slopes, hence providing the right conditions for anticyclonic vorticity and formation of low potential vorticity water in the bottom boundary layer. The separation of the undercurrent from the slope excites submesoscale instabilities, which eventually interact and merge to form a largerscale eddy (Molemaker et al. 2015; Thomsen et al. 2016; Contreras et al. 2019). Gula et al. (2015) found a contribution of both, horizontal Reynolds stress and vertical eddy fluxes, toward the source of eddy kinetic energy (EKE) along the southeastern path of the Gulf Stream.

In the eastern tropical North Atlantic (ETNA), the region off northwestern Africa $\left(12^{\circ}-22^{\circ} \mathrm{N}, 15^{\circ}-26^{\circ} \mathrm{W}\right)$ experiences upwelling-favorable winds from December to April, which are modulated by the seasonal migration of the intertropical convergence zone (Mittelstaedt 1983, 1991; Brandt et al. 2015). The seasonality in the winds also influences the oceanic flow field (Klenz et al. 2018), resulting in a poleward undercurrent with surface equatorward coastal jets during the upwelling season (December-April) and poleward surface current (upper $250 \mathrm{~m}$ ) during the relaxation period (MayJuly). Eddies that spin off colder and fresher thermocline water masses of ultimately South Atlantic origin advected northward with the poleward undercurrent feed into the
ETNA thermocline region (Jones and Folkard 1970; Pastor et al. 2008; Glessmer et al. 2009; Peña-Izquierdo et al. 2015). As a result, a contrasting regime between North Atlantic Central Water (NACW), formed in the subduction regions of the North Atlantic subtropical gyre, and the modified South Atlantic Central Water (SACW) emanating from the Mauritanian upwelling region, is created and is strongest in the Cape Verde frontal zone (Tomczak 1981; Brandt et al. 2015). The large-scale impact of the local extremes in second-order baroclinic mode eddies is, for example, manifested in the creation of a shallow oxygen minimum at about $80 \mathrm{~m}$ in the ETNA (Schütte et al. 2016b), distinct from the deeper minimum at about $450 \mathrm{~m}$ which is often associated with the core of the oxygen minimum zone (OMZ; Brandt et al. 2015; Karstensen et al. 2008).

Eddy occurrence in the ETNA has been studied using satellite-derived sea surface height data and applying different eddy tracking algorithms (Cardoso et al. 2018; Chaigneau et al. 2009; Chelton et al. 2007; Schütte et al. 2016a). Using 19 years (1995-2013) of satellite altimetric data, Schütte et al. (2016a) reported on average 150 eddies per year in the ETNA, with cyclones, anticyclones, and anticyclonic mode water eddies (ACMEs) occurrences of 52\%, 39\%, and 9\%, respectively. The study also found that the second-order baroclinic mode ACMEs contributed largely to the offshore transport of SACW, with an anomaly of $+50 \%$ of SACW in their cores, compared to $+30 \%$ for CEs, and ACEs consisting of water masses comparable to their surroundings (Schütte et al. 2016a). In reference to local eddy confined dynamical processes, ACMEs showed respiration rates of at least 10 times higher than the surrounding waters and are responsible for strong oxygen drawdown and creation of almost anoxic environments (Fiedler et al. 2016; Karstensen et al. 2015). For the ETNA, eddy generation hotspots were found close to the coast, associated with the headlands of Cap-Vert (Senegal; $14.75^{\circ} \mathrm{N}$ ) and Cap Timiris (Mauritania; $19.38^{\circ} \mathrm{N}$ ) (Chaigneau et al. 2009; Schütte et al. 2016a). Also, a seasonality in eddytype-dependent generation was observed, with CEs, ACEs, and ACMEs shedding off mostly in June, July, and AprilMay, respectively (Schütte et al. 2016a). This observed seasonality was hypothesized to be associated with a seasonal strengthening and hence more unstable Mauritania Current. However, little is known about the instability processes that lead to eddy formation in the ETNA. One case study associated the generation of a submesoscale cyclonic eddy, at the Cap-Vert headland, with an intermittent wind burst, which induced a strengthening of the surface flow, hence leading to a flow separation (Alpers et al. 2013).

The aim of the paper is to investigate the dynamical conditions for the generation of eddies (CEs, ACEs, and ACMEs) in the near-coastal region of the ETNA using a high-resolution $(\sim 1.5-\mathrm{km}$ horizontal grid size) ocean model. The nearcoastal region is defined as the area between the $50-\mathrm{m}$ isobath and $1.5^{\circ}$ offshore from the $50-\mathrm{m}$ isobath. The paper is organized as follows: in section 2 , the different datasets (model and observations) are described as well as an eddy tracking algorithm is introduced. Section 3a evaluates the model's capability in realistically resolving the regional dynamical 
features and the eddy structures for the ETNA region. In section $3 b$, the seasonal variability of eddy genesis is assessed. Particular attention is paid to the vorticity fluxes during the generation of negative vorticity (ACEs and ACMEs) and positive vorticity (CEs). Finally, the results are summarized in section 4.

\section{Data and methods}

\section{a. Modular Ocean Model}

Our model configuration is based on the Geophysical Fluid Dynamics Laboratory (GFDL) Modular Ocean Model (MOM), version MOM4p1 (Griffies et al. 2009), which is a free-surface ocean general circulation model discretizing the ocean's hydrostatic primitive equations on a fixed Eulerian grid. The model domain covers most of the subtropical gyre in the North Atlantic $\left(15.5^{\circ}-60^{\circ} \mathrm{W}, 6.25^{\circ}-38.5^{\circ} \mathrm{N}\right)$. The boundaries are solid walls and there are no horizontal boundary conditions such as restoring. The meridional and zonal resolutions are a function of longitude and latitude, respectively. Within the Mauritanian upwelling region $\left(15.5^{\circ}-20^{\circ} \mathrm{W}\right.$, $14^{\circ}-22^{\circ} \mathrm{N}$ ), the horizontal resolution increases up to values between 1.4 and $1.7 \mathrm{~km}$. This suggests that the model configuration fully resolves the generic processes with spatial scales corresponding to the first baroclinic Rossby radius of deformation ( 40-60 km). Such a telescoping spatial grid was used earlier, e.g., in the MOM Southern Ocean (MOMSO) setup (Dietze et al. 2020). The vertical discretization comprises 75 levels on a pressure-based coordinate, the "pstar" $\left(p^{*}\right)$ coordinate system. These 75 levels are spaced at $10-\mathrm{m}$ intervals in the first $600 \mathrm{~m}$, increasing to a (capped) maximum of $1500 \mathrm{~m}$ over the whole domain. The horizontal discretization is an Arakawa B-grid, comprising of $1427 \times 1159$ tracer grid points.

The underlying bathymetry is derived from the Earth topography five-minute grid (ETOPO5) and is interpolated onto the Arakawa B-grid using a bilinear scheme. It is then smoothed with a filter similar to the Shapiro filter (Shapiro 1970). The model is initiated from rest with temperature and salinity data from the World Ocean Atlas 2009 (Antonov et al. 2010; Locarnini et al. 2010). The atmospheric forcing is climatological: Corrected Normal Year Forcing (COREv2; Large and Yeager 2004) featuring an annual cycle of all the data needed to force an oceanic model and can be applied repeatedly for many years (Griffies et al. 2009; Large and Yeager 2009). The simulation's outputs are averaged daily over three climatological years. Outputs from the first year, the spinup period, are discarded. Analyses presented in this study refer to subsequent nominal years two and three. Note that because of computational cost, the spinup is short compared to regional (smaller than gyre scale with open boundaries) configurations such as presented by Marchesiello et al. (2003), Capet et al. (2004), Kurian et al. (2011), and Colas et al. (2013). On the upside, this ensures that our thermocline conditions remain close to observed initial conditions (because model drift is permitted less time to manifest itself). On the downside, this raises the question if our simulation is sufficiently equilibrated. As for the latter, we argue that for our region of interest, the strong seasonality in the dynamics of the system challenges the concept of equilibration. Or, in other words, we prioritize staying close to observed initial conditions over ensuring equilibration to a potentially biased state.

In terms of subgrid-scale parameterization, we apply the $k$-profile parameterization approach of Large et al. (1994) with a critical bulk Richardson number of 0.3 , and a constant vertical background diffusivity and viscosity of $10^{-5} \mathrm{~m}^{2} \mathrm{~s}^{-1}$. These background values are also employed below the surface mixed layer throughout the water column. Both parameterizations of the nonlocal and the double diffusive (vertical) scalar tracer fluxes are applied. We apply a state-dependent horizontal Smagorinsky viscosity scheme (Smagorinsky 1963, 1993; Griffies and Hallberg 2000) to keep friction at the minimal level necessitated by numerical stability. The scale of the Smagorinsky isotropic viscosity is set to 0.01 , and we do not apply any explicit horizontal diffusivity.

\section{1) RATIONALE FOR OUR CONFIGURATION}

To date, we cannot afford to run a decade-long spinup with a global submesoscale-resolving general ocean circulation model. As the small-scale variability is central to our research question, we are left with the options to shorten the spinup (to less than the typical decades) or to confine the model domain regionally by introducing boundary conditions, or both. The effects of initial conditions and boundary conditions are related to the length of the model integration. The longer the integration, the stronger the effect of the boundary conditions and the weaker the effect of the initial conditions. Both the initial and boundary conditions are potentially introducing spurious model behavior, since they may be inconsistent with the internal dynamics resolved during integration. In our experience, issues with boundary conditions can be especially cumbersome and lead to unrealistic water mass conversion rates in the model domain.

In this study, we take a pragmatic approach, keeping computational costs down to feasible levels. This comes at the cost of some (implicit) assumptions. Confining our model domain to $1500-\mathrm{m}$ water depth reduces the barotropic time step and associated computational burden. By doing so, we assume that the deep circulation has only a minor effect on the near-surface processes, which are our main interest. Additionally, the model domain covers most of the subtropical gyre in the North Atlantic and since the gyre time scale is on the order of decades, the effect of initial conditions prevails over the effect of boundary conditions on time scales on the order of years, which is all that we can afford with the available computational resources. Hence, the quality of our simulation is closely tied to the quality of our initial conditions (and forcing at the air-sea interface). This poses a problem because the high variability in the regions of interest would call for an especially highly resolved observational database in order to derive dynamically consistent initial conditions, which does not exist. Here, we take again a pragmatic approach and use climatological temperature and salinity only. Initial velocities 
are set to zero. We find that after the spinup period, the simulated seasonal variability in surface properties exceeds the interannual differences, and further, that the simulated eddy kinetic energy exceeds altimetric observations. Note, however, that our simulation is not representative of an equilibrated climatology but rather, provides a model-aided extrapolation of climatological initial conditions to an instance of dynamical conditions off Mauritania.

\section{b. Observational datasets}

\section{1) HYDROGRAPHIC DATA}

We use data composed of hydrography and currents (vessel mounted acoustic Doppler current profiler; vmADCP) from nine research cruises, performed in the ETNA between March 2005 and August 2016, for comparison with model data at the $18^{\circ} \mathrm{N}$ zonal transect. See Klenz et al. (2018) for a complete description of the cruises and access to the data. Here we focus on two mean time periods to describe the seasonal variability of hydrography and the Mauritania Current, namely, the upwelling (December-April) and relaxation (May-July) seasons.

\section{2) SATELlite DATA}

Absolute surface geostrophic velocities were obtained from the Copernicus Marine and Environment Monitoring Service (CMEMS; http://marine.copernicus.eu). These are merged products from multiple altimeters (Ducet et al. 2000), and data from the observation period (2005-16) at $0.25^{\circ}$ horizontal grid resolution were acquired to supplement the vmADCP data in the surface layer.

Optimally interpolated sea surface temperature (SST) daily maps of merged through-cloud microwave data at high spatial resolution and mostly near-coastal capability of infrared SST data were provided by the Remote Sensing Systems website (http://www.remss.com) at a 9-km horizontal resolution.

\section{c. Eddy detection and tracking algorithm}

The angular momentum eddy detection and tracking algorithm (AMEDA; Le Vu et al. 2018) is used to track simulated eddies in order to determine eddy genesis locations and their propagation paths. The algorithm has been used for global (e.g., de Marez et al. 2020) and regional studies including the ETNA (Cardoso et al. 2018). AMEDA is applied here to the spatially filtered (25-point boxcar filter) 100-m depth model velocity fields and that allow the identification of both surface- and subsurface-intensified eddies, while suppressing smaller-scale features. The algorithm starts with identifying the eddy center by seeking an extremum in the local normalized angular momentum (LNAM), a dynamical parameter with maxima at eddy centers $(+1$ for cyclonic and -1 for anticyclonic), which is independent of eddy intensity (Mkhinini et al. 2014). The streamlines associated with the velocity fields, around the LNAM maxima, are then computed. The mean velocity $(V)$ and radius $(R)$ for each streamline are evaluated, with an increasing azimuthal speed toward the eddy perimeter until maximum speed is reached $\left(V_{\max }\right)$. The corresponding radius is $R_{\max }$, also known as speed radius (Chelton et al. 2011a; Laxenaire et al. 2018; Le Vu et al. 2018). The azimuthal speed then decreases down to the last detected velocity streamline. Next, the algorithm tracks each individual eddy, based on the combination of a global cost function and a modified version of the "local nearest-neighbor" search, which links each detected eddy $e_{i}$ at time step $t$ with the nearest eddy $e_{j}$ of similar sign at time step $t-d t$, within a given search area. This search area relies on both the theoretical distance an eddy can travel during the period $d t$ and the maximum propagation speed of $e_{i}$, set at $6.5 \mathrm{~km} \mathrm{day}^{-1}$. Finally, events of merging and splitting of eddies are identified. A merging event occurs when two individual eddies are encompassed by a closed streamline (shared contour) and one of the two eddy trajectories end after their interaction period. A splitting event happens when a closed contour splits into two smaller closed contours and only one trajectory was present before the interaction period.

Because we were interested not only in polarity (either as cyclonic or anticyclonic) but also in eddy vertical mode structure and stratification to distinguish between ACEs and ACMEs (Chaigneau et al. 2011; Pelland et al. 2013; Schütte et al. 2016a), further analysis on the eddies identified with AMEDA were required. Our additional analysis on anticyclonic vortices considered Ertel's potential vorticity and the percentage content of SACW within the vortex. The Ertel's potential vorticity is defined as

$$
\mathrm{PV}=(\zeta+f \mathbf{z}) \times \nabla b,
$$

where $\zeta=\nabla \times \mathbf{u}$ is the relative vorticity, $\mathbf{z}$ is the vertical unit vector, $\mathbf{u}=(u, v, w)$ is the velocity vector with components in the zonal, meridional, and vertical axes; and $b=-g \rho / \rho_{0}$, where $b, f, g, \rho$, and $\rho_{0}$ are the buoyancy, Coriolis parameter, gravitational speed, density, and a reference density $(1025 \mathrm{~kg}$ $\mathrm{m}^{-3}$ ), respectively.

To quantify the water mass content in eddies, we perform a simple water mass analysis accounting for endmember mixing along isopycnals (e.g., Klenz et al. 2018). End-members are chosen from the model's temperature and salinity profile data in the Mauritanian upwelling region $\left(20^{\circ}-15.5^{\circ} \mathrm{W}, 15^{\circ}-21^{\circ} \mathrm{N}\right)$. The two extremes along isopycnals (fresh and cold versus warm and saline) are associated with the dominant regional water masses, namely, SACW and NACW. Anticyclonic vortices with low PV cores (defined here as less than $5 \times 10^{-10} \mathrm{~s}^{-3}$ ) and a SACW content higher than $50 \%$ are qualified as being ACMEs and all others as ACEs.

\section{Results and discussion}

\section{a. Model evaluation}

\section{1) MAURITANIAN UPWELLING REGION CIRCULATION}

The seasonal migration of the intertropical convergence zone determines the upwelling-favorable winds in the region (e.g., Brandt et al. 2015; Klenz et al. 2018), with the main upwelling season lasting from January to March. During that period, a coastal equatorward flow at the surface prevails from $17^{\circ}$ to $22^{\circ} \mathrm{N}$, a feature which is reasonably well captured in the 

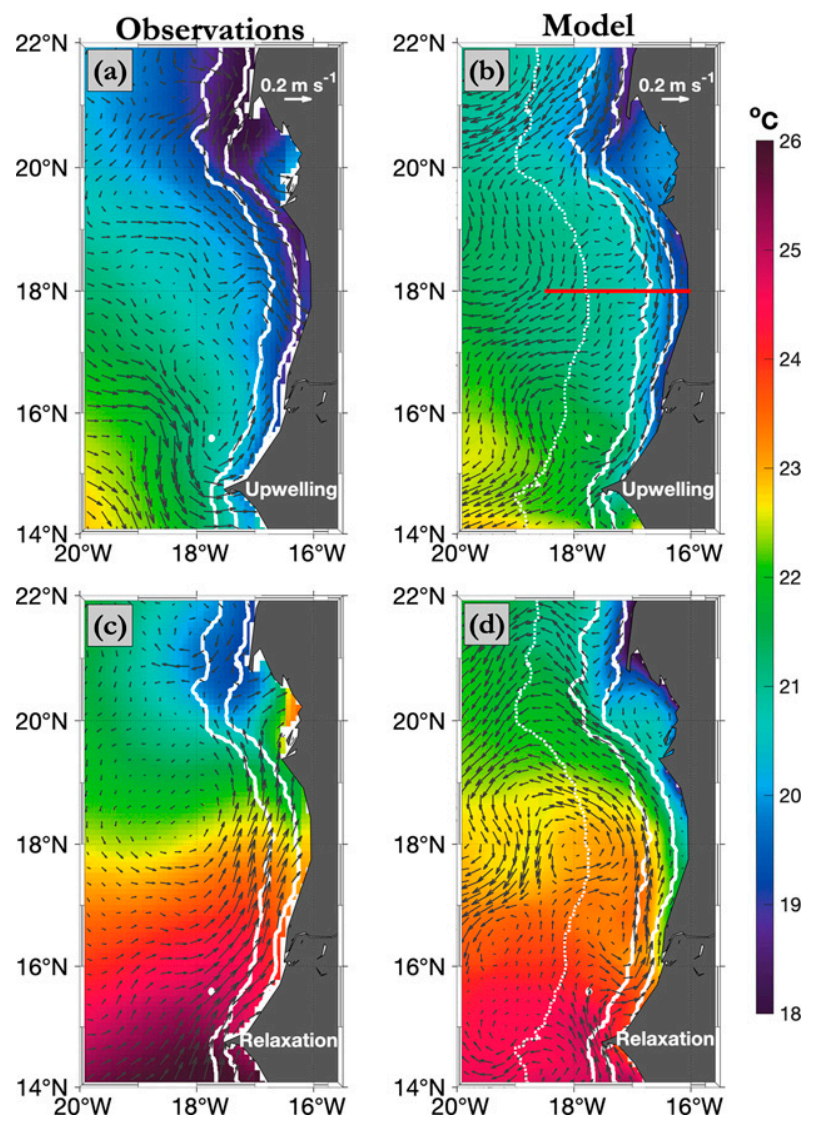

FIG. 1. Mean observed sea surface temperature $\left({ }^{\circ} \mathrm{C}\right)$, superimposed with surface geostrophic velocities $\left(\mathrm{ms}^{-1}\right)$ from AVISO during (a) upwelling (January-March) and (c) relaxation (MayJuly) seasons. (b),(d) As in (a) and (c), but from the model outputs. The white contours indicate the 50- and $1000-\mathrm{m}$ isobaths. The red line in (b) indicates the zonal transect of the sections in Fig. 2. The white dotted line in (b) and (d) designates the near-coastal region, identified as $1.5^{\circ}$ from the $50-\mathrm{m}$ isobath.

simulation (Figs. 1a,b). Between $15^{\circ}$ and $17^{\circ} \mathrm{N}$, a continued equatorward flow is present in the model whereas observations indicate the existence of a poleward flow and linked to a closed circulation cell centered at $16.5^{\circ} \mathrm{N}, 18^{\circ} \mathrm{W}$. During the relaxation period (May-July), when the trade winds weaken, a poleward surface current, the Mauritania Current (MC), is evident in observations and model data alike (Figs. 1c,d). The MC is predominantly driven by the cross-shore wind structure (Munk 1950) and as such flows against the equatorward winds (Klenz et al. 2018). As for the surface flow, the model also retraces most the SST variability during both the upwelling (RMSE = $0.75^{\circ} \mathrm{C}$, bias $=0.66^{\circ} \mathrm{C}$ ) and relaxation $\left(\mathrm{RMSE}=0.73^{\circ} \mathrm{C}\right.$, bias $=$ $-0.01^{\circ} \mathrm{C}$ ) periods.

Comparing observations and model hydrography and flow along a section at $18^{\circ} \mathrm{N}$ (Fig. 2), we find good agreement during the upwelling (salinity: RMSE $=0.1$ psu and bias $=-0.05 \mathrm{psu}$; temperature: $\mathrm{RMSE}=1.2^{\circ} \mathrm{C}$ and bias $=0.36^{\circ} \mathrm{C}$ ) and the relaxation (salinity: $\mathrm{RMSE}=0.11 \mathrm{psu}$ and bias $=-0.02 \mathrm{psu}$; temperature: $\mathrm{RMSE}=0.88^{\circ} \mathrm{C}$ and bias $=0.03^{\circ} \mathrm{C}$ ) periods. In regard to the upwelling season, the model reproduces the main vertical features along $18^{\circ} \mathrm{N}$, with a decreasing surface salinity from offshore toward the onshore (Figs. 2a,b). Lower temperature is observed close to the shelf, indicative of the active winddriven upwelling, although the $20^{\circ} \mathrm{C}$ isotherm outcrops closer to the coast in the model (Fig. 2a) compared to observations (Fig. 2a). However, the depths of the 26.3 and $26.8 \mathrm{~kg} \mathrm{~m}^{-3}$ isopycnals are well represented in the model. Throughout the relaxation period (Figs. 2c,d), the model overestimates the offshore surface salinity $(0-100 \mathrm{~m})$, possibly due to the local recirculation observed at $18^{\circ} \mathrm{N}, 18^{\circ} \mathrm{W}$ (Fig. 1d), which could contribute to an input of excess NACW. Nonetheless, an intrusion of fresher waters is perceived in the simulated upper Central Water (uCW; 25.8-26.8 $\mathrm{kg} \mathrm{m}^{-3}$ ), analogous to observations. The model also represented fairly well the input of lower salinity waters close to the coast during the upwelling season, compared to the relaxation one.

Interestingly, the two cores of the observed poleward undercurrent during the upwelling season are well captured by the model, although these are shifted $\sim 0.2^{\circ} \mathrm{E}$ longitudinally and slightly deeper in the model (Figs. 2e,f) relative to the observations. Comparable to observations, a near-surface equatorward flow can be noted on the shelf, although it is slightly expanded and stronger. The relative strength of this surface jet as well as the poleward undercurrent depends on the intensity of the wind stress and wind stress curl, as proposed by theoretical and modeling studies (Capet et al. 2004; McCreary et al. 1987). Throughout the relaxation season, the seasonal intensification of wind stress curl induces a surfaceintensified poleward flow, with the equatorward surface jet vanishing. This poleward flow is correctly resolved in the simulation, with a slight underestimation of its strength (Fig. $2 \mathrm{~g}, \mathrm{~h})$. Associated to this flow is a rapid warming of near coastal SSTs, as perceived by the isotherms in Figs. 1c and 1d. A common characteristic of EBUS is the presence of an equatorward current below the poleward current (Chaigneau et al. 2013; Tchipalanga et al. 2018), which is also present in the Mauritanian upwelling region (Klenz et al. 2018) and reproduced by the simulation. Overall, we conclude a good agreement in regional dynamical and hydrographic features in the observational and the model data, which provide confidence for subsequent process analysis using the model outputs.

\section{2) EDDY VERTICAL STRUCTURES AND MEAN PROPERTIES}

To assess the model's capability in reproducing the vertical structures of eddies in the Mauritanian upwelling region, we analyzed exemplary eddies of each type (CE, ACE, and ACME) and compared them with observations (Schütte et al. 2016a). The ability of the eddies to trap specific water mass anomalies is estimated by computing the potential temperature and salinity anomalies in reference to monthly mean profiles located $120 \mathrm{~km}$ to the east and west of the eddy centers (similar to Schütte et al. 2016a). The reference profiles are taken on the same latitude as the eddy center to account 

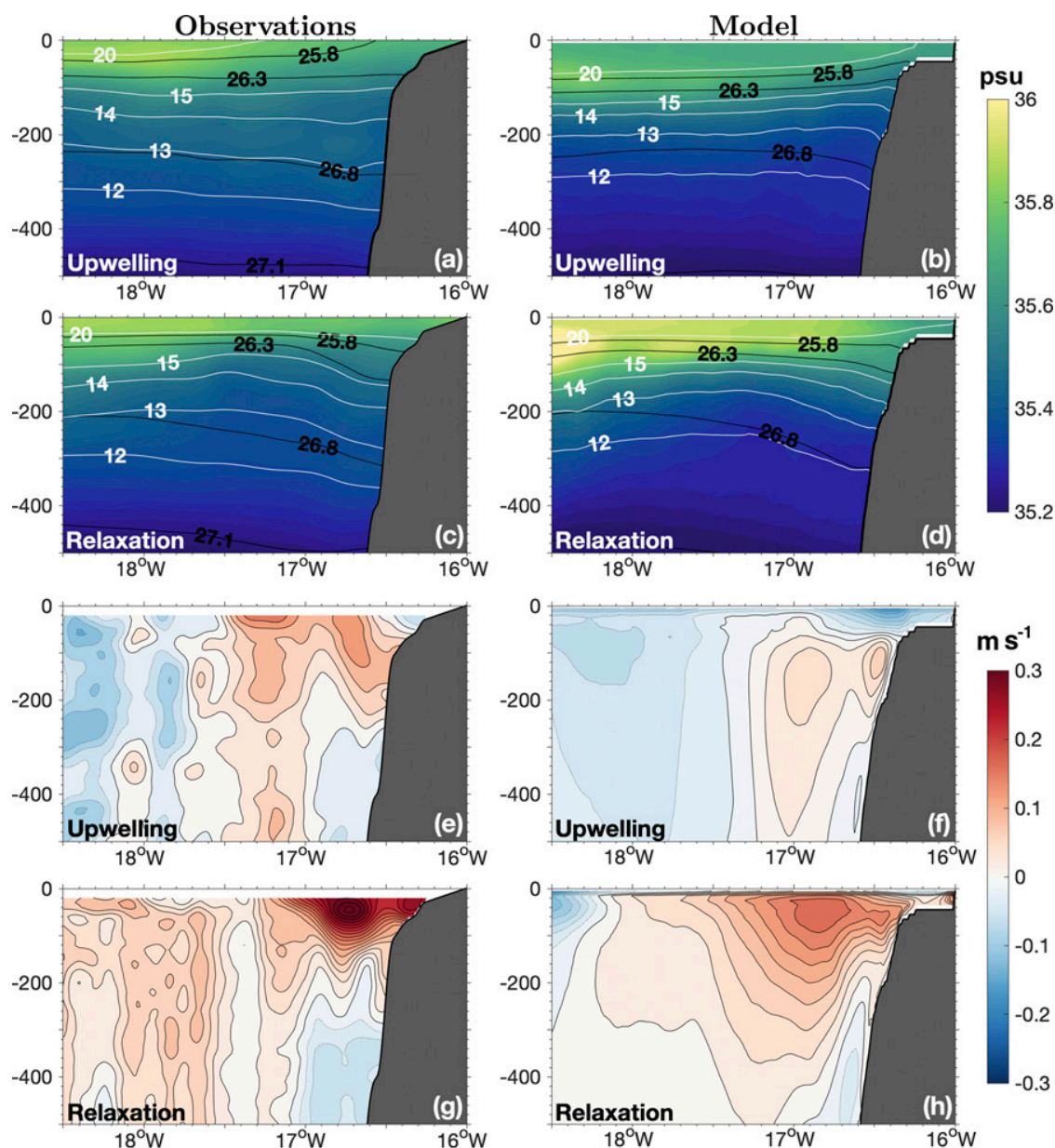

FIG. 2. Vertical structure of (a)-(d) mean salinity (psu) and (e)-(h) mean alongshore velocities (positive poleward; $\mathrm{m} \mathrm{s}^{-1}$ ) along the $18^{\circ} \mathrm{N}$ zonal section (red line in Fig. 1b) from (left) observations and (right) model, during upwelling and relaxation periods. White contours in (a)-(d) represent mean temperature $\left({ }^{\circ} \mathrm{C}\right)$, and black contours show isopycnals $\left(\mathrm{kg} \mathrm{m}^{-3}\right)$.

for the regional meridional temperature-salinity $(T-S)$ gradients.

The CE shows a rather barotropic structure with a clear signature of rotation down to about $1500 \mathrm{~m}$ (only up to $500 \mathrm{~m}$ is shown here). The core contains cold and fresher water mass anomalies (Figs. 3b,c), due to the ability of CEs in trapping, on average, $+16 \%(+30 \%$ in their cores $)$ anomaly of SACW compared to their surroundings (Schütte et al. 2016a). The vertical upward displacements of isopycnals also indicate possible intrusions of colder and fresher water mass within the CE. However, positive surface salinity anomaly is seen in the simulated CE, possibly associated with the offshore presence of NACW. ACEs were reported to host water mass of NACW attributes in their cores (Schütte et al. 2016a), hence the positive temperature and salinity anomalies observed (Figs. 3g,h). The ACE has a baroclinic velocity structure with highest velocities at about 150-200 m (Fig. 3i), coinciding with a maximum in $T / S$ anomalies. The ACME shows a baroclinic velocity structure also manifested in the associated tilting of isopycnals. Low stratification is centered at $26.55 \mathrm{~kg} \mathrm{~m}^{-3}$ and isopycnals bending upward for lighter water $\left(26.5 \mathrm{~kg} \mathrm{~m}^{-3}\right.$ shoals to $\sim 75 \mathrm{~m}$ ) and downward for denser water $\left(26.6 \mathrm{~kg} \mathrm{~m}^{-3}\right.$ deepens to $\sim 215 \mathrm{~m}$ (Fig. 3o). ACME and CE exhibit similar water mass signature in their cores, but with the maximum absolute anomaly being twice as large in ACME. This contrast can be due to ACME hosting local water mass anomalies along isopycnals, and not perturbed by vertical disturbances of the density fields as it is the case for the CE.

The maximum temperature anomaly is $-2.20^{\circ} \mathrm{C}$ at $107 \mathrm{~m}$ for the $\mathrm{CE}$ and $4.07^{\circ} \mathrm{C}$ at $96 \mathrm{~m}$ for the $\mathrm{ACE}$, whereas the maximum salinity anomaly is $-0.48 \mathrm{psu}$ at $107 \mathrm{~m}$ for the $\mathrm{CE}$ and $0.30 \mathrm{psu}$ at $177 \mathrm{~m}$ for the ACE, both comparing well with observations in respect to magnitude and depth (Schütte et al. 2016a). The nonlinearity parameter $\alpha$ is a measure for coherence and relates the maximum rotational velocity to the translation speed (e.g., Chelton et al. 2011a). 


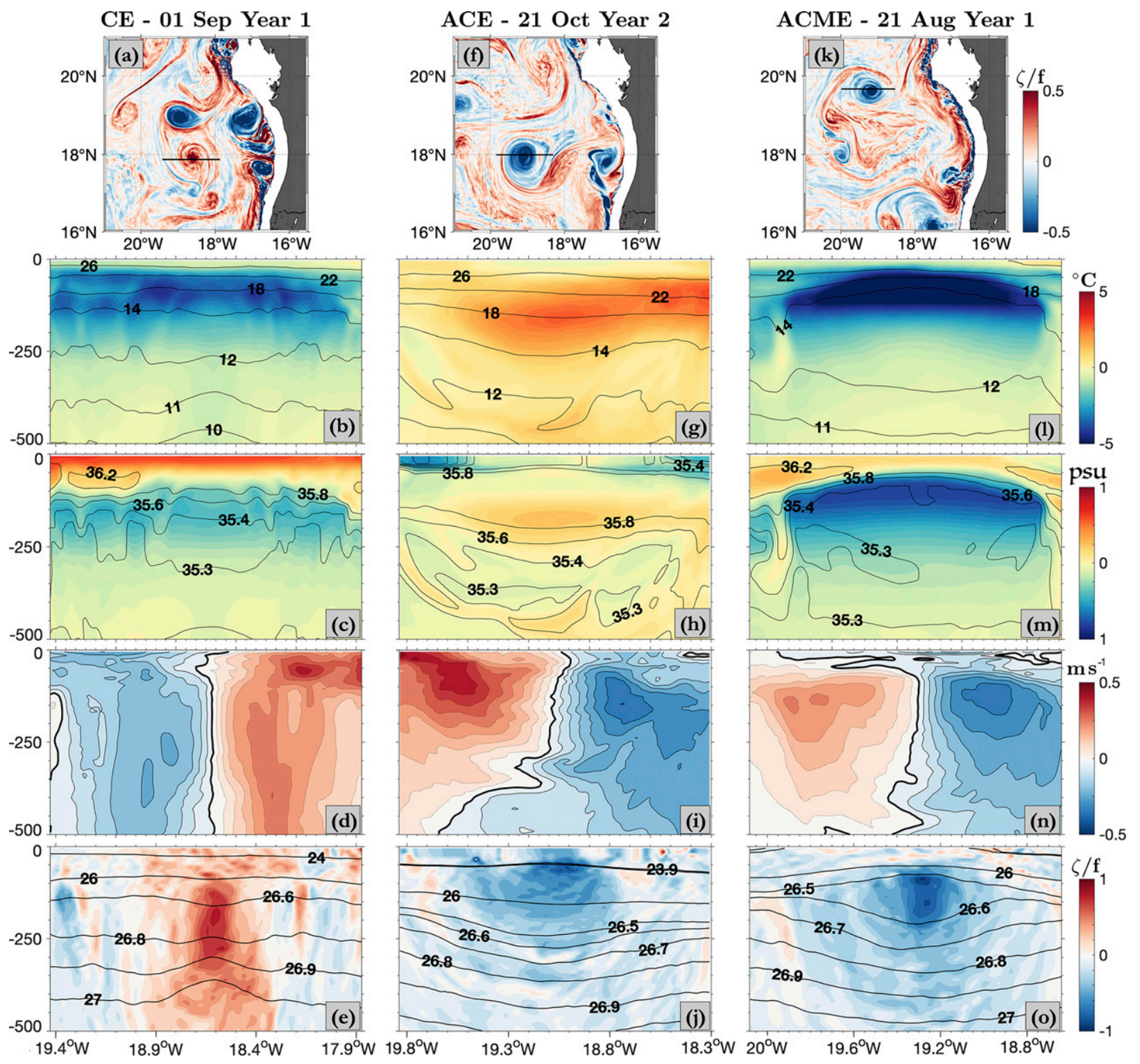

FIG. 3. Snapshots of relative vorticity (normalized by Coriolis parameter) at 100-m depth, during the mature phase of three eddies: (a) cyclonic eddy, (f) anticyclonic eddy, and (k) anticyclonic mode water eddy. The vertical sections of (b),(g),(l) temperature anomalies with mean potential temperature as black contours; (c),(h),(m) salinity anomalies with mean salinity as black contours; (d),(i),(n) meridional velocity with thick black lines indicating the change in northward component; and (e),(j),(o) the relative vorticity normalized by Coriolis parameter with mean potential density as black contours, for each eddy types [black zonal transect in (a), (f), and (k)]. The anomalies are calculated in reference to mean monthly profiles $120 \mathrm{~km}$ to the east and west of the eddy center.

For the ACME core, an $\alpha$ of 4.3 is found at $140-\mathrm{m}$ depth where the maximum rotational speed is located and is indicative for an isolated core (Fig. 3n). The model ACME $\alpha$ is comparable to those reported for the oxygen-depleted ACME ( 6.5-11 at depth of low- $\mathrm{O}_{2}$ core) in the region (Karstensen et al. 2017).

Further, we assessed the occurrences for the three different types of eddies (Table 1). Because of the high resolution of the model, small $(<20 \mathrm{~km})$ and short lived $(<1$ week) eddies were also generated but were ignored in the statistics. In total 84 eddies were identified in the two years of simulation, with CEs, ACEs, and ACMEs accounting for $51 \%, 25 \%$, and $24 \%$ of the total number, respectively. From satellite data, Schütte et al. (2016a) reported 52\% CE, $39 \%$ ACE, and 9\% ACME. However, because of their second baroclinic mode structure, the ACMEs are expected to show only a weak signature in sea level anomaly ( $\mathrm{Li}$ et al. 2017) and thus may explain the lower number as derived 
TABLE 1. Mean properties of cyclonic, anticyclonic and anticyclonic mode water eddies ( \pm standard deviation), with a minimum lifetime of 1 week and with radius $>20 \mathrm{~km}$, detected in the domain of interest $\left(15.5^{\circ}-22^{\circ} \mathrm{W}, 14^{\circ}-22^{\circ} \mathrm{N}\right)$, and in the near-coastal region (within $1.5^{\circ}$ to the $50-\mathrm{m}$ isobath; shown in italics).

\begin{tabular}{lccr}
\hline \hline & Cyclones & Anticyclones & Anticyclonic mode water \\
\hline Number of eddies detected & 43 & 21 & 20 \\
& 12 & 9 & 17 \\
Average lifetime (days) & $77.1 \pm 68.2$ & $89.9 \pm 80.6$ & $85.7 \pm 59.9$ \\
& $71.8 \pm 66.9$ & $78.1 \pm 67.5$ & $91.8 \pm 61.4$ \\
Average radius $(\mathrm{km})$ & $40.5 \pm 10.4$ & $34.0 \pm 13.4$ & $31.6 \pm 13.2$ \\
& $38.2 \pm 11.9$ & $27.2 \pm 7.3$ & $29.1 \pm 11.8$ \\
\hline
\end{tabular}

from observational data. Our analysis also showed that within the near-coastal region, more ACMEs are identified compared to CEs and ACEs, hence providing an indication that ACME formation might be related to a near-coastal process, possibly instabilities of the boundary current resulting from interactions with the local topography.

We found a longer lifetime of the simulated eddies compared with studies based on observational data (Schütte et al. 2016a). Simulated ACEs outlive ACMEs and CEs, with a mean lifetime of $\sim 90$ days, compared to $\sim 86$ days for ACMEs and $\sim 77$ days for CEs, respectively. In observations, ACEs have been shown to outlive CEs, as they tend to be more robust and prone to merge with other ACEs, while CEs manifest a higher tendency to self-destruction (Cushman-Roisin and Tang 1990; Chaigneau et al. 2009; Chelton et al. 2011a). Furthermore, ACME cores are isolated from surface processes by the strong stratification at the base of the mixed layer, and hence may be mostly shielded from surface buoyancy fluxes. It should be noted that ACMEs generated in the near-coastal region survive longer in comparison to ACEs and CEs. As expected from the degradation on eddy characteristics through the sampling and interpolation procedures (Amores et al. 2018), the average simulated eddy radius is much smaller scale $(35.4 \pm 12.3 \mathrm{~km})$, compared to eddies identified from satellite altimetry data $(56 \pm 12 \mathrm{~km}$; Schütte et al. (2016a)).

\section{b. Eddy generation}

\section{1) REGIONAL AND SEASONAL VARIABILITY}

Before investigating the dynamical processes that govern the eddy generation, we analyzed the temporal and spatial variability of eddy generation. The location of eddy generation is identified by counting in $1^{\circ} \times 1^{\circ}$ boxes the initial detection of each eddy. Hotspots of eddy generation close to the coast, namely, near Cap-Vert $\left(14.75^{\circ} \mathrm{N}\right)$, slightly north of Saint-Louis $\left(\sim 17^{\circ} \mathrm{N}\right)$, Cap Timiris $\left(19.38^{\circ} \mathrm{N}\right)$, and Cap Blanc $\left(20.76^{\circ} \mathrm{N}\right)$, and in the Cabo Verde region (around $16^{\circ} \mathrm{N}, 22^{\circ} \mathrm{W}$ ) are found (Fig. 4a). These hotspots are in agreement with those reported based on observational data (Schütte et al. 2016a; Cardoso et al. 2018). Coastal regions, especially within an upwelling system, are prone to mesoscale variability (Chelton et al. 2011a; Frenger et al. 2018). The hotspot in the Cabo Verde region, which is not the subject of this study, has been found to be linked to the incoming background eddies and atmospheric effects, namely, wind-work within island wakes (Cardoso et al. 2018).

Cyclones are more evenly generated over the whole region, with hotspots near Cap-Vert, Cap Timiris, and the Cabo Verde region (Fig. 4b). Anticyclones have preferred generation location slightly north of Saint-Louis and toward Cap Blanc region (Fig. 4c). The main generation locations of ACMEs are concentrated close to the coast (Table 1) but with a maximum off Saint-Louis and Cap Blanc (Fig. 4d). This coastal maximum provides a further indicator that coastal processes may be the main generation mechanism for ACMEs.

The monthly latitudinal variability of anticyclonic eddy genesis inshore of $19^{\circ} \mathrm{W}$ shows a pronounced seasonality with a peak during boreal summer (June-August; Figs. 4g,h). ACE generation peaks in August (Fig. 4g), compared to June for ACMEs (Fig. 4h). The near-surface Mauritania Current is particularly strong (Lázaro et al. 2005; Klenz et al. 2018) during that period, suggesting that dynamic instabilities of the boundary current are a key generation mechanism for these eddies. The peak generation of cyclonic eddies occurs in April and December (Fig. 4f). The seasonality of CE generation is at odds with observational evidence presented by Schütte et al. (2016a), who proposed a summertime peak in $\mathrm{CE}$ generation. As a cautionary note in respect to the Schütte et al. (2016a) study, there are known shortcomings in terms of reliability of satellite altimetry products in coastal areas (Vignudelli et al. 2011) and for eddy characterization (Amores et al. 2018). However, our statistics have to be considered with caution also since they are based on two years of model data only, and hence may be obscured by interannual variability.

\section{2) ENERGY AND STABILITY OF THE BOUNDARY CURRENT}

The local topography has been found, in earlier studies, to play a key role in instability processes by indirectly altering the stability properties of boundary currents as the Mauritania Current (Røed 1980; Gula et al. 2015; Molemaker et al. 2015). Moreover, nonlinear interactions between the mean flow and eddies also provide an important mechanism that influences the strength, structure, and stability of the mean current (Gula et al. 2015).

To understand the instability processes that generate eddies in the Mauritanian upwelling region, we analyzed 

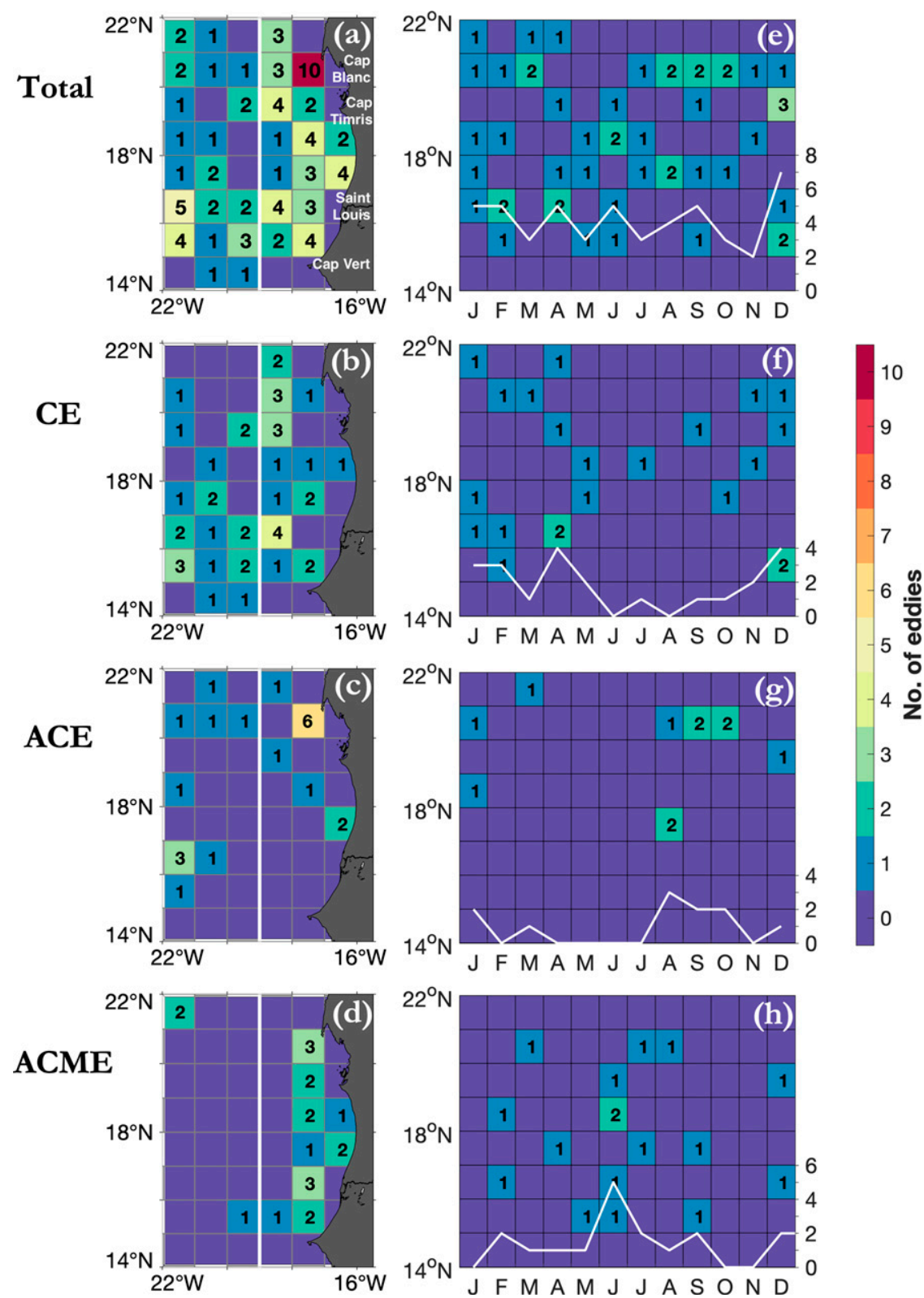

FIG. 4. (left) The number of eddies generated in a $1^{\circ} \times 1^{\circ}$ box and (right) the monthly latitudinal variability of number of eddies generated in the region inshore of the $17^{\circ} \mathrm{W}$ (white lines in left panels). The number of eddies is displayed in each grid cell and is associated to specific color codes. The white lines in right panels display the monthly variability (sum over latitudes) of eddy generation, inshore of $17^{\circ} \mathrm{W}$. Only eddies with a minimum lifetime of 1 week and radius greater than $20 \mathrm{~km}$ are considered.

the seasonal variability of the sources of eddy energy from the model data. For the analysis, we separated variables $(A)$ into a monthly mean $(\bar{A})$ from the 2-yr model dataset and a fluctuation $\left(A^{\prime}\right)$ with relative to that mean. The sources of eddy energy are the terms associated to the transfer of mean kinetic and potential energy between the mean and eddy flows, also known as barotropic and baroclinic instabilities. The conversion of mean kinetic energy (MKE) to eddy kinetic energy (EKE) can be divided into contributions from the horizontal (HRS) and vertical (VRS) Reynolds stresses (Gula et al. 2015), written as $K_{m} K_{e}=$ HRS + VRS where

$$
\mathrm{HRS}=-\overline{u^{\prime 2}} \frac{\partial \bar{u}}{\partial x}-\overline{u^{\prime} v^{\prime}} \frac{\partial \bar{u}}{\partial y}-\overline{v^{\prime 2}} \frac{\partial \bar{v}}{\partial y}-\overline{u^{\prime} v^{\prime}} \frac{\partial \bar{v}}{\partial x},
$$


represents the product of horizontal mean shear and horizontal Reynolds stress, and

$$
\mathrm{VRS}=-\overline{u^{\prime} w^{\prime}} \frac{\partial \bar{u}}{\partial z}-\overline{v^{\prime} w^{\prime}} \frac{\partial \bar{v}}{\partial z},
$$

arises from the vertical shear of the mean flow and vertical Reynolds stress. The eddy potential energy (EPE) to EKE conversion is the vertical eddy buoyancy flux

$$
P_{e} K_{e}=\overline{w^{\prime} b^{\prime}}
$$

where $b$ is the buoyancy anomaly relative to the local average. From scaling analysis (not shown here), it becomes clear that VRS is one order of magnitude smaller than HRS and $P_{e} K_{e}$, and as such is neglected in the analysis. For the analysis, HRS and $P_{e} K_{e}$ are integrated over the region with water depth between 50 and $300 \mathrm{~m}$, corresponding to the interaction zone between the Mauritania Current and the slope (Figs. 2f,h) and avoiding transient processes in the surface mixed layer (integration in the 100-300-m depth range did not show any significant spatial differences).

A positive barotropic instability (HRS) arises from large horizontal gradients of velocity, hence a transfer of energy from the mean flow to the mesoscale eddy kinetic energy. On the other hand, baroclinic instability $\left(P_{e} K_{e}\right)$ emerges from large horizontal density gradients which create strong vertical gradients of the horizontal velocities through the thermal wind relation. The flow is unstable and lateral exchange of properties occurs to reduce the horizontal gradients of density, essentially through transferring energy from available potential energy reservoir to eddy kinetic energy (Marchesiello et al. 2003; Gula et al. 2015).

During the relaxation period (boreal summer), alongshore winds are weakened but wind stress curl intensifies, inducing a strengthening of the poleward flowing Mauritania Current. The coastal current starts to increase from May at $16^{\circ} \mathrm{N}$ and reaches its maximum between the latitudinal range of $16.3^{\circ}-17.2^{\circ} \mathrm{N}$ (near Saint-Louis) in August (Fig. 5a). A reduced speed is then observed downstream of $17.2^{\circ} \mathrm{N}$, coinciding with topographic curvatures (see isobaths in Fig. 6), hence forcing the current to meander offshore.

In general, the baroclinic conversion $\left(P_{e} K_{e}\right.$; Fig. 5c) exhibits a larger amplitude in parallel to the barotropic one (HRS; Fig. 5b), both linked to an intensification of the Mauritania Current in boreal summer. The signature in the energy terms gives insight into the importance of baroclinicity in the system and hence, the primary eddy generation mechanism can be linked to the baroclinic instabilities of the alongshore current. This is analogous to eddy generation in the California Current System, where baroclinic instability induced by alongshore currents have been shown to be the dominant mechanism for eddy genesis (Marchesiello et al. 2003). However, both the HRS and $P_{e} K_{e}$ undergo alongshore variations that can be explained by the topographic effect on the energy conversion terms. The flow pressing against the slope induces an increased shear due to inertia effects and topographic curvatures (Gula et al. 2015). The transfer of energy from the transient wind to eddy kinetic energy $\left[F_{e} K_{e}\right.$; $\left.F_{e} K_{e}=\left(1 / \rho_{0}\right)\left(\overline{u^{\prime} T_{x}^{\prime}}+\overline{v^{\prime} T_{y}^{\prime}}\right)\right]$ was also considered but not shown, as its magnitude is smaller than the sum of HRS and $P_{e} K_{e}$, which indicates the predominance of instabilities generated from the boundary current toward eddy generation.

Positive fluxes of $P_{e} K_{e}$ arise downstream of strongest signature in the Mauritania Current speed (Figs. 5a,c), indicating an overshooting and destabilization of the boundary current leading to enhanced instabilities. The positive $P_{e} K_{e}$ patches coincide with sharp topographic changes along the boundary, with sharp curvatures of the 500- and 1000-m isobaths at around $14.9^{\circ}, 17.2^{\circ}$, and $19.8^{\circ} \mathrm{N}$ (see isobaths in Fig. 6). These positive fluxes are followed by negative patches, as observed at $15^{\circ}-17^{\circ} \mathrm{N}, 17^{\circ}-19.5^{\circ} \mathrm{N}$, and $20^{\circ}-21.5^{\circ} \mathrm{N}$ (Fig. $5 \mathrm{c}$ ), where the flux of energy is toward the eddy potential. In boreal summer, a strongest Mauritania Current along the $17.2^{\circ} \mathrm{N}$ topographic bend result in the strongest positive signature of $P_{e} K_{e}$ downstream. Most cyclonic/anticyclonic vorticity structures are generated at this latitudinal band (Figs. 4a,e), with some of them developing into eddies straightaway while others propagate poleward with the boundary current before evolving and detected as eddies by the eddy tracking algorithm.

\section{3) CONNECTING ENERGY BUDGET AND EDDY GENERA- TION HOTSPOTS: SELECTED CASES}

The link between the energy budget analysis and eddy generation is assessed in this section, as well as the generation mechanisms for a selected case of ACME, ACE, and CE. The annual mean spatial variability of both HRS and $P_{e} K_{e}$ exhibits large alongshore variations along the coast (Fig. 6), because of the mean flow constantly pressing against the slope or detaching from it at topographic curvatures (Gula et al. 2015). The sharp topographic bend at $20^{\circ} \mathrm{N}$ results in enhanced horizontal shear instabilities (Figs. $6 \mathrm{a}-\mathrm{c})$. Thus, a hotspot of eddy generation exists downstream of this $20^{\circ} \mathrm{N}$ topographic variation (Figs. $4 \mathrm{a}-\mathrm{d}$ and Fig. 6), indicating the possible importance of transfer of mean kinetic energy toward eddy kinetic energy.

The baroclinic conversion term displays a patch of positive signal at $18^{\circ} \mathrm{N}$, from the slope until at least the $1.5^{\circ}$ from the $50-\mathrm{m}$ isobath line (near-coastal region) (Figs. 6d-f). As reported in the previous section, this patch is associated with the destabilization of the mean current at the critical orographic curvature at $17.2^{\circ} \mathrm{N}$, with the offshore extension of the patch corresponding to the overshooting of the current (Fig. 1d). Eddy generation at topographic variations has been observed in other EBUS (Molemaker et al. 2015; Thomsen et al. 2016; Contreras et al. 2019) as well as in the Gulf Stream region (Gula et al. 2015) and in the Agulhas region (Tedesco et al. 2019). The generation of ACMEs is mostly confined along the topography (Figs. 6c,f) in the Mauritanian upwelling region. This signature is expected since subsurface eddies are characterized by low PV waters, and the bottom boundary layer is known to be a source of low PV (McWilliams 1985; D'Asaro 1988; Molemaker et al. 2015), as will be shown further. 

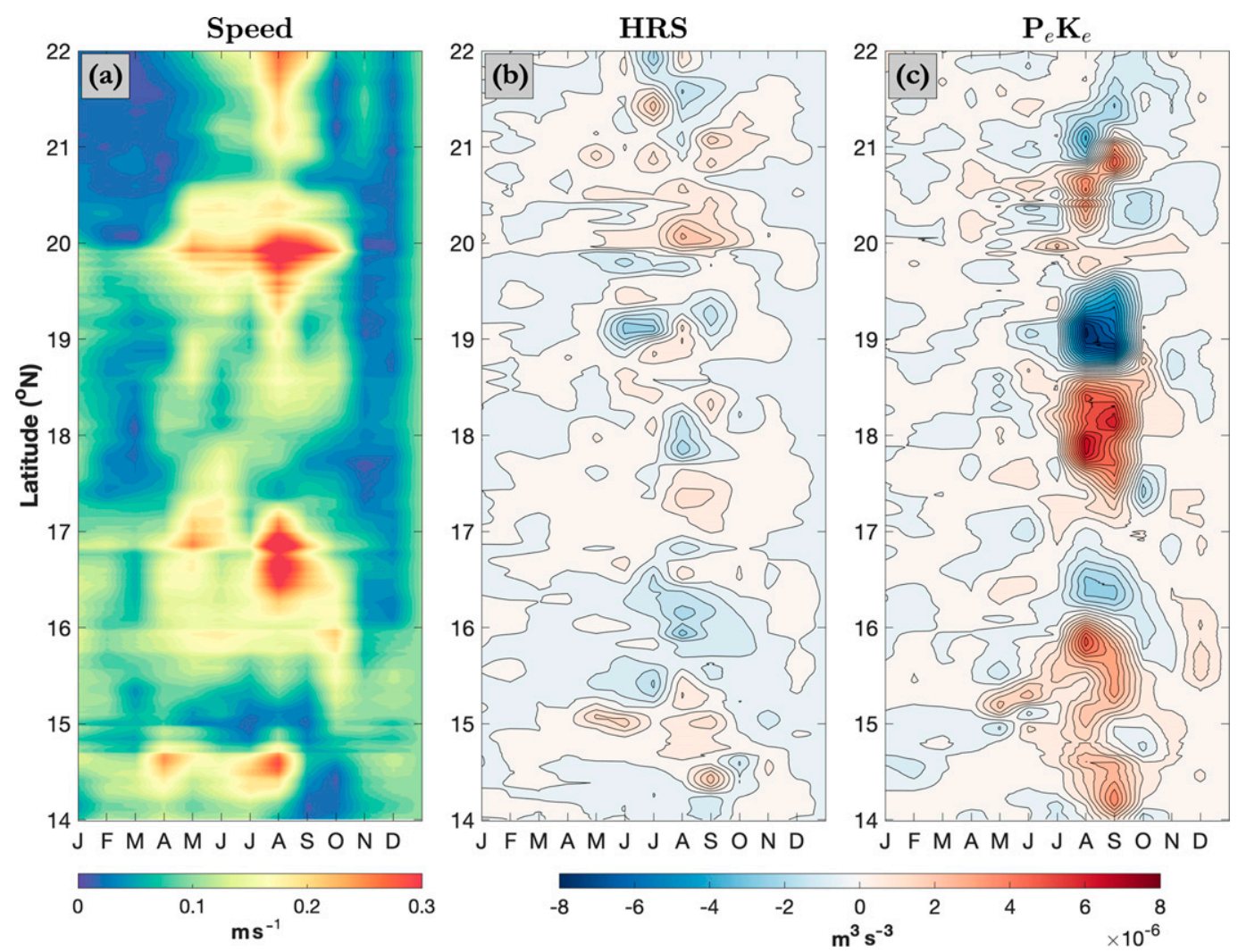

FIG. 5. Hovmöller diagram of monthly latitudinal variability of (a) current speed at 100-m depth and (b) HRS and (c) $P_{e} K_{e}$ integrated over the 50-300-m depth. The current speed is spatially averaged between the 100- and 1000-m isobath to isolate the current-topography interaction region. HRS and $P_{e} K_{e}$ are spatially averaged within the near coastal region (1.5 from the 50-m isobath), to capture the offshore signature of $P_{e} K_{e}$, as seen in Fig. 6. HRS and $P_{e} K_{e}$ have been smoothed using a $10-\mathrm{km}$ convolution low-pass filter.

\section{4) ANTICYCLONIC VORTICITY GENERATION}

Subsurface eddies have been shown to manifest anticyclonic vorticity in the Mauritanian upwelling region (Karstensen et al. 2017; Schütte et al. 2016a,b) and in other EBUS (Contreras et al. 2019; Frenger et al. 2018; Molemaker et al. 2015; Thomsen et al. 2016). This anticyclonic vorticity signature can originate from the bottom boundary layer of the poleward flowing boundary current that flows over the slope (D'Asaro 1988; Molemaker et al. 2015). Along the slope, the Mauritania Current is rapidly reduced, generating large horizontal $(\partial \mathbf{V} / \partial x)$ and vertical shear $(\partial \mathbf{V} / \partial z)$ components ( $\mathbf{V}$ being the alongshore flow), and hence the vertical component of the vorticity in the bottom boundary layer is anticyclonic.

The generation of anticyclonic vorticity from interactions between the mean current and slope during boreal summer (June-August) is analyzed at six cross-shore sections along the Mauritanian coast (Fig. 7g). At sections a, c, and e, the poleward flowing boundary current is close to the slope, with the speed reducing drastically in the sloping boundary current, and hence creating a narrow band of negative vertical vorticity on the slope (Figs. 7a,c,e). Downstream of these sections (sections $\mathrm{b}, \mathrm{d}$, and $\mathrm{f}$, respectively), the negative vorticity bands are not present along the slope since the boundary current meanders offshore and is not attached to the bottom slope. These are the regions where enhanced instabilities occur, and hence are hotspots for eddy generation (Fig. 4a), which are fed with negative vorticity generated just upstream. The important alongshore variability of the negative boundary layer vorticity (Fig. 7g) can be related to sharp topographic variations and corresponding changes in the form drag (Gula et al. 2015; Molemaker et al. 2015).

\section{5) FORMATION OF ACMEs}

Subsurface anticyclonic eddies are known to be characterized by very low PV waters in their cores, which are thought to play a critical role during their formation (McWilliams 1985; D'Asaro 1988; Molemaker et al. 2015). In the absence of tracer and/or momentum mixing, PV is conserved and is consequently ideal to identify and track water masses (Thomsen et al. 2016). PV is calculated as in Eq. (1), and since $f$ is positive in the Northern Hemisphere, positive (negative) PV values reflect stable (unstable) conditions with respect to symmetric instability (Hoskins 1974). Thus, we multiply PV with 

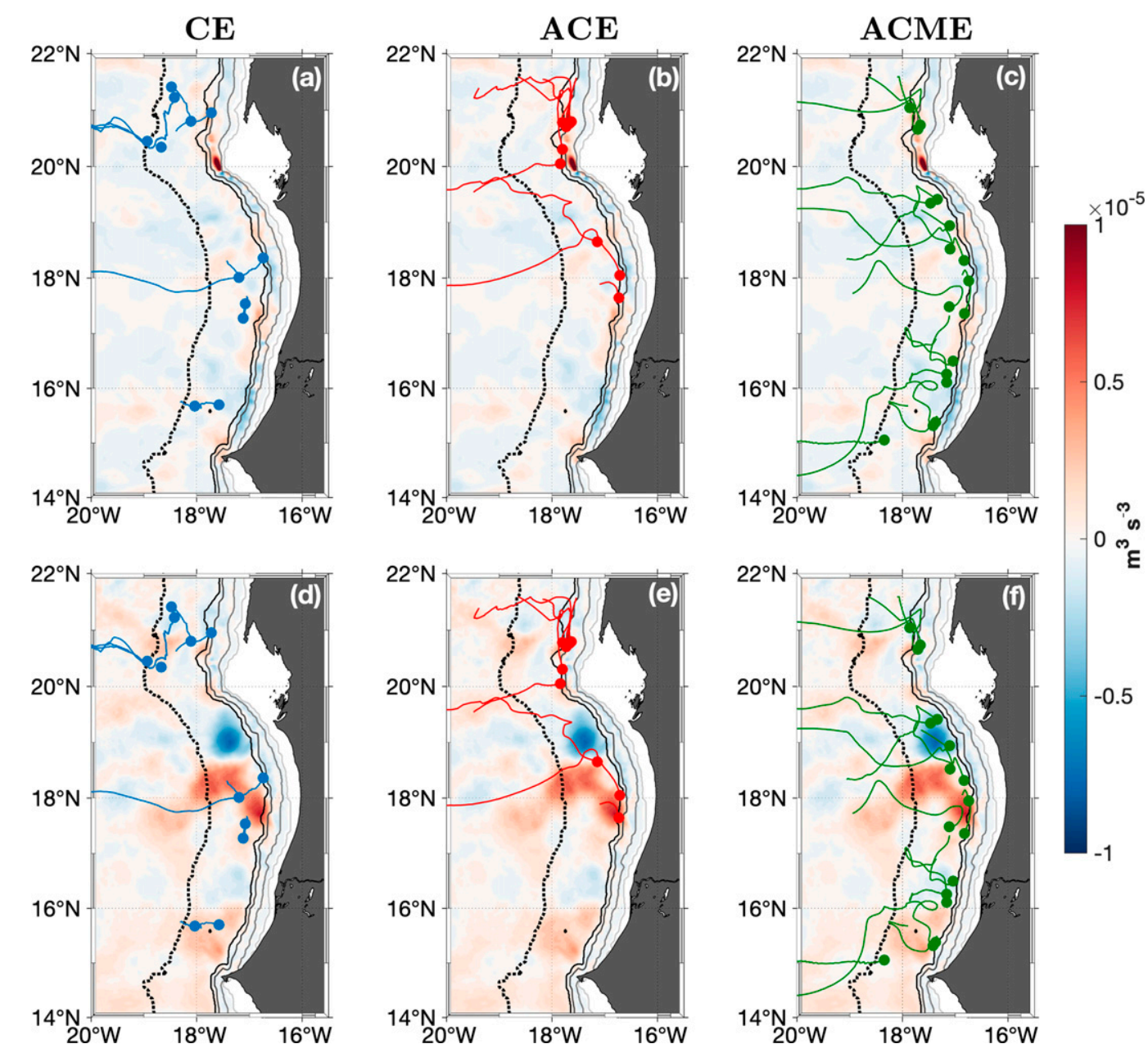

FIG. 6. Annual climatology of (top) HRS and (bottom) $P_{e} K_{e}$ integrated over the 50-300 m depth, with the generation location and tracks of (a),(d) cyclonic eddies; (b),(e) anticyclonic eddies; and (c),(f) anticyclonic mode water eddies. HRS and $P_{e} K_{e}$ have been smoothed using a 10-km convolution low-pass filter. The light gray to black contours show the 50-, 100-, 500-, and 1000-m isobaths, with the black dotted line indicating the $1.5^{\circ}$ from the $50-\mathrm{m}$ isobath (near-coastal region).

the local Coriolis parameter $f(f \mathrm{PV})$ for better comparison with previous studies, and we shall hereafter refer to $f \mathrm{PV}$ as $\mathrm{PV}$ for easier interpretation. The bottom boundary layer has been shown to act as a source or sink for PV over the bottom slope, depending on the direction of the current interacting with the slope (Williams and Roussenov 2003). In the Mauritanian upwelling region, the circulation of the Mauritania Current is in the same direction as Kelvin wave propagation (Polo et al. 2008), so the downslope Ekman flow will advect less dense water under denser water, driving diabatic mixing and reducing the magnitude of PV (Benthuysen and Thomas 2012).

The interaction of the Mauritanian Current with the slope and its role in the formation of an ACME at $19.32^{\circ} \mathrm{N}, 16.9^{\circ} \mathrm{W}$ is analyzed below. Prior to the intensification of the boundary current (10 May; Figs. 8a,b), the core of the current is located slightly offshore at $\sim 100-\mathrm{m}$ depth, with a velocity of $\sim 0.2 \mathrm{~m} \mathrm{~s}^{-1}$. A small strip of negative vorticity with low PV waters can be observed along the slope (Fig. 8b). On 22 May, the boundary current strengthens to $\sim 0.45 \mathrm{~m} \mathrm{~s}^{-1}$, with the core closer to the slope. This strengthening is also discernable by the upward and downward bent of the 26.5 and 26.8 $\mathrm{kg} \mathrm{m}^{-3}$ isopycnals close to the coast. The interaction of the increased boundary current and the slope creates a larger band of negative vorticity with close to zero PV (Fig. 8d), with the low PV water signatures extending beyond the boundary layer. This signature, far from the boundary layer, prompts the flow to become unstable and hence generating inertial instability (Thomas et al. 2013). The boundary current then separates from the slope with an anticyclonic vorticity core in the depth range between 60 and $260 \mathrm{~m}$. The low PV patch is no longer restricted to the region on the slope (Fig. 8f) and starts to increase in size through the coalescence of submesoscale structures formed when the boundary current becomes unstable (Molemaker et al. 2015; Contreras et al. 2019). An 

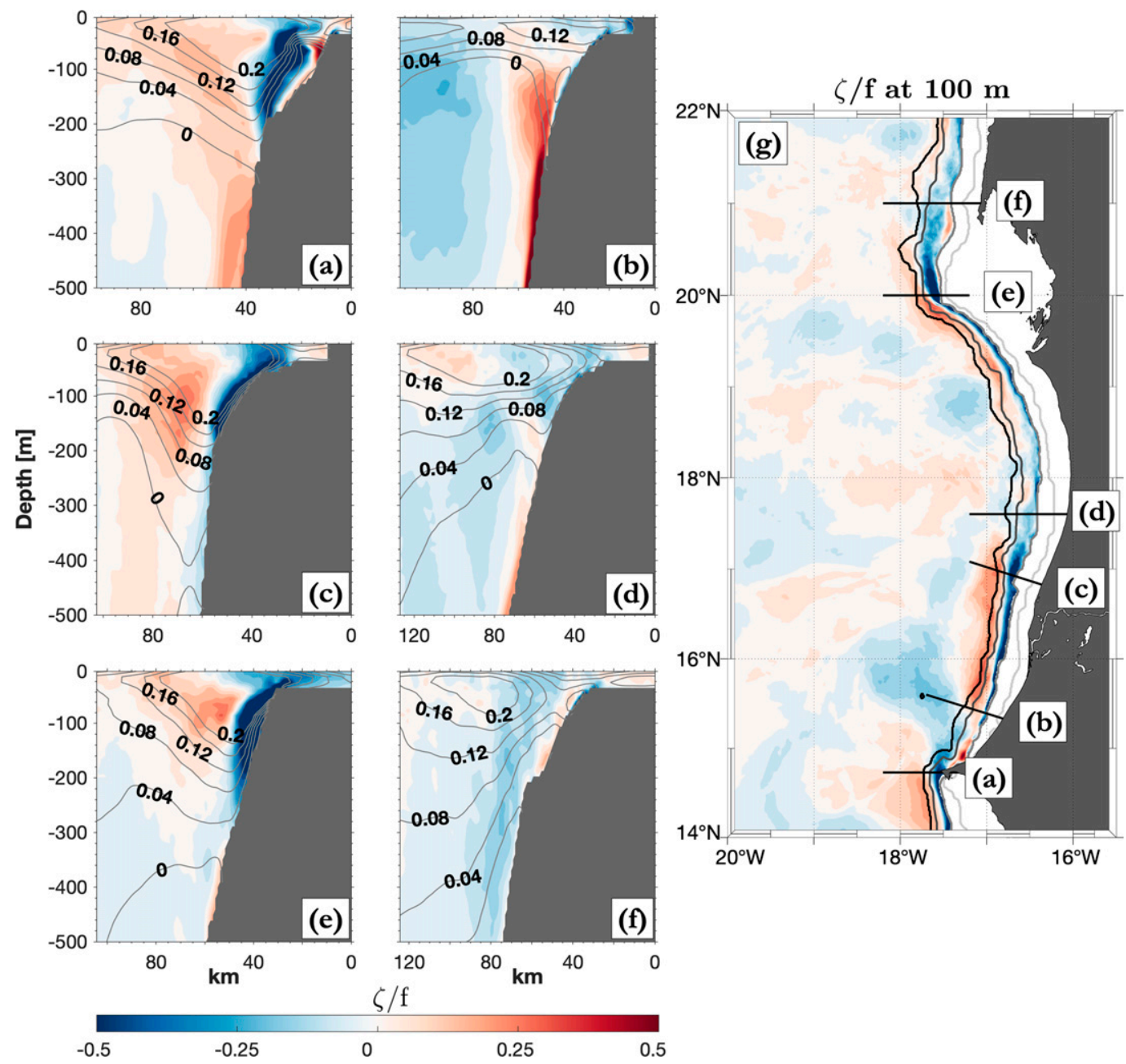

$-0.25$

0 0.5

FIG. 7. (a)-(f) Vertical sections of the relative vorticity (normalized by Coriolis parameter) with alongshore velocity speed $\left(\mathrm{m} \mathrm{s}^{-1}\right)$ in gray lines at six sections along the Mauritanian coast. Note that the scale of the $x$ axis in each section is different. (g) The relative vorticity (normalized by Coriolis parameter) at 100-m depth, with the black lines indicating sections (a)-(f). The relative vorticity and the alongshore currents are averaged over the June-August period. The light gray to black contours show the 50-, 100-, 500-, and 1000-m isobaths.

equatorward flow develops at around $17^{\circ} \mathrm{W}$ (Fig. 8e), becoming a component of the ACME structure. From 10 June, the ACME structure is well developed and is no longer restricted to the coast. It exhibits a shoaling of the $26.5 \mathrm{~kg} \mathrm{~m}^{-3}$ and deepening of the $26.6 \mathrm{~kg} \mathrm{~m}^{-3}$ isopycnal (Figs. $8 \mathrm{~g}-\mathrm{j}$ ), with minimum $\mathrm{PV}$ values in its core. It ultimately propagates westward as a coherent structure with an isolated low PV core.

The interaction of the boundary current with sharp topographic variations leading to flow separation and the generation of subsurface coherent anticyclonic eddies is in agreement with the study of D'Asaro (1988) and the high-resolution modeling experiment in the Californian upwelling region by Molemaker et al. (2015). The importance of a frictional boundary layer and development of low PV signatures on the topography of the continental slope prior to anticyclonic eddy formation was also suggested in these previous studies (D'Asaro 1988; Molemaker et al. 2015) and is in line with our findings, as waters with low PV signature is found on the slope of the topography due to an intensification of the boundary current and its interaction with the slope, with the low PV waters eventually ending up within the core of the ACME. This supports the findings that the bottom boundary layer is an important source region of water mass characteristics within eddy cores and hence is analogous to subsurface eddy generation processes in the Peru-Chile Current system, from previous observations (Thomsen et al. 2016) and a modeling study (Contreras et al. 2019). However, it is required that the boundary layer detaches from the slope at topographic bend and transport the negative vorticity offshore. The specific processes involved in the separation from the slope in the Mauritanian upwelling region are not analyzed here. Different 
mechanisms can lead to a boundary current separation, namely, the so-called $\beta$ effect, stretching of vortex tubes (Marshall and Tansley 2001; Thomsen et al. 2016), as well as changes in topography (Molemaker et al. 2015; Contreras et al. 2019).

\section{6) FORMATION OF ACES}

In most cases, ACEs are characterized with maximum rotational velocity within the surface layers and decreasing toward the deeper layers. However, this is not always the case as observed in Fig. 3i, where maximum rotational velocity is found at $\sim 100-150 \mathrm{~m}$ for an ACE. Hence, from this perspective, ACMEs are not the only eddy type with maximum velocity in the subsurface layers. However, the distinct differences between an ACE and an ACME are the weak stratification and the high SACW content within the ACME core. The previous section has shown that negative vorticity is generated through the interaction between the Mauritania Current and the slope, with the current becoming unstable at abrupt topography curvatures. However, any other possible factor that defines an anticyclonic vorticity structure to develop into an ACE or an ACME is still undetermined. This is explored by analyzing the generation of two exemplary ACEs and two ACMEs, and we hypothesize that wind-driven coastal upwelling can play a critical part in it.

Previous studies have shown that the water mass distribution at the continental slope in the Mauritanian upwelling region is bounded by a lower $\left(25.8 \mathrm{~kg} \mathrm{~m}^{-3}\right)$ and upper potential density $\left(27.1 \mathrm{~kg} \mathrm{~m}^{-3}\right)$, that is further divided into upper Central Water (uCW; 25.8-26.8 $\mathrm{kg} \mathrm{m}^{-3}$ ) and lower Central Water (1CW; 26.8-27.1 $\mathrm{kg} \mathrm{m}^{-3}$ ) (Fischer et al. 2013; Johns et al. 2003; Stramma et al. 2005). Klenz et al. (2018) showed that the uCW consisted of $\sim 70 \%-80 \%$ SACW during the upwelling season and $\sim 80 \%-90 \%$ SACW during the relaxation season, whereas lCW incorporates less than $50 \%$ SACW during these seasons.

The meridional $\left(V^{\mathrm{ek}}\right)$ and zonal $\left(U^{\mathrm{ek}}\right)$ Ekman transport, based on the Bakun upwelling index (Bakun 1973, 1975), is computed to investigate the influence of wind-driven transport on the water mass characteristics prior to an anticyclonic structure formation. The zonal and meridional component of the Ekman transport is calculated as follows:

$$
V^{\mathrm{ek}}=\frac{-\tau^{x}}{\rho_{0} f}, \quad U^{\mathrm{ek}}=\frac{\tau^{y}}{\rho_{0} f},
$$

where $\tau^{x}$ and $\tau^{y}$ are the zonal and meridional wind stress components, respectively. These are then converted to the offshore Ekman transport, at the latitudinal location of the eddy.

The offshore Ekman transport is computed within a box englobing the eddy shape at its first detection date, and 1 month prior to the eddy formation as well as 10 days after (right panels in Fig. 9). From the distribution of SACW content along the zonal sections, higher SACW content is revealed with the ACMEs generation period in comparison to the ACEs (center panels in Fig. 9), with uCW being slightly shallower during ACMEs generation period (Figs. 9d,h). Both ACMEs can be identified by a low PV core within a doming and bowling isopycnals, located at around $17^{\circ} \mathrm{W} / 90 \mathrm{~m}$ (Fig. 9d) and $16.8^{\circ} \mathrm{W} / 140 \mathrm{~m}$ (Fig. 9h), with higher than 50\% SACW in their cores. As expected, no coherent signature of low PV can be observed for the two ACEs, with the bowling of the $26.5 \mathrm{~kg} \mathrm{~m}^{-3}$ isopycnal (Figs. 9b,f) revealing the position of the eddy cores.

Overall, the initial-eddy detection location of the ACME-1 experienced mostly stronger offshore Ekman transport for $\sim 19$ days prior to the eddy identification relative to the ACE1 (Fig. 9i). A similar trend in offshore Ekman transport is observed for the ACME-2 (Fig. 9j) with transport at the ACME-2 location twice as high in some instances compared to ACE-2. Strong offshore Ekman transport entails a coastal upwelling of water mass characteristics of SACW in the area of current-topography interactions, leading to eddy cores of different water mass characteristics. The background SACW content can also potentially be influenced through the northward advection of that water mass in the boundary current system, prior to eddy formation. ACMEs present a low PV core composed of relatively dense SACW whereas ACEs contain less dense NACW. With an offshore propagation of the eddies into the regional background stratification, the relatively dense low PV cores in ACMEs will be subducted and shielded from the surface buoyancy forces. In contrast, the lighter ACE cores will remain closer to the surface and hence, will be influenced by surface buoyancy forcing, altering the stratification and breaking down the PV.

\section{7) FORMATION OF CES}

The model reveals the occurrence of cyclonic eddies to be associated with perturbations of the flow due to the presence of anticyclonic vortices in the Mauritanian upwelling region. Two distinct CEs are investigated, and the sequence of their generation are shown in the top and bottom panels of Fig. 10, respectively. Ten days before the $\mathrm{CE}$ generation (Fig. 10a), an ACE is well formed and located slightly offshore $\left(18.3^{\circ} \mathrm{N}\right.$, $17.8^{\circ} \mathrm{W}$ ), with the boundary current exhibiting a weakly poleward flow along the boundary. A patch of positive relative vorticity developed between the weak poleward boundary flow and the equatorward rotating flow associated with the ACE. At $t=-5$ days, the poleward boundary current strengthens, with the flow meandering away from the slope owing to the topographic curvatures. This meander, together with the southeastern side of the ACE, develops into a cyclonic rotation with enhanced positive relative vorticity at $17.7^{\circ} \mathrm{N}, 17^{\circ} \mathrm{W}$ (Fig. 10b). At this stage, the CE is formed and is detected on 1 January (Fig. 10c). Ten days later, the ACE has propagated westward, advecting the $\mathrm{CE}$ away from the coast, while a stronger boundary current continues its way downstream along the coast.

The generation of the second CE (bottom row in Fig. 10) occurs in boreal summer when the Mauritania Current is at its strongest intensity. At $t=-10$ days, strong instabilities in the boundary current can be observed, with three anticyclonic vorticity structures present, with an ACE identified by the eddy tracking algorithm at $18.9^{\circ} \mathrm{N}, 17.3^{\circ} \mathrm{W}$ (Fig. 10e). Cyclonic circulation exists between these three structures, leading to enhanced positive relative vorticity. At $t=-5$ days, the identified ACE structure coalesces with the upstream vorticity 

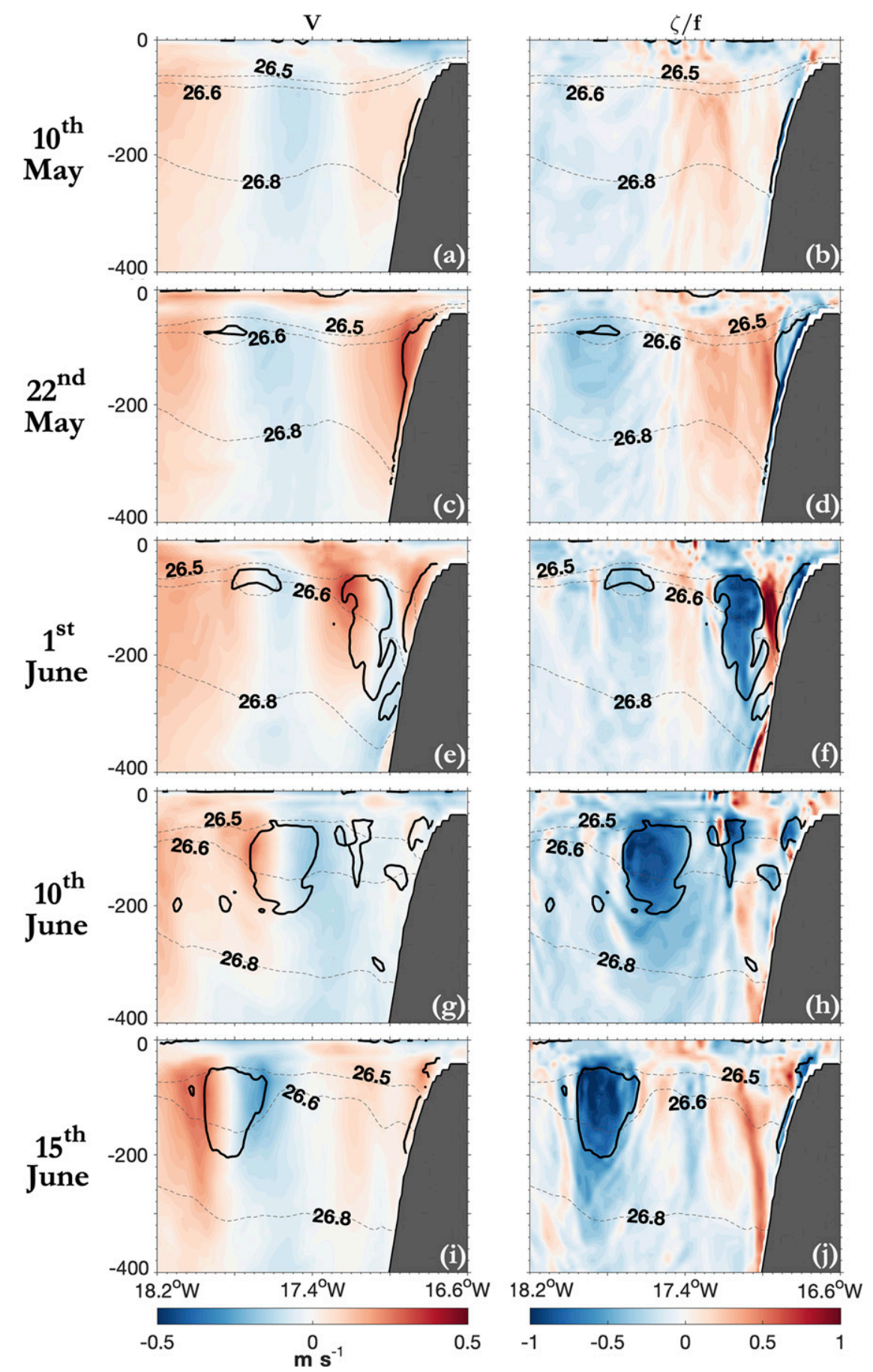

FIG. 8. Snapshots of vertical sections at $19.32^{\circ} \mathrm{S}$, showing the temporal evolution of (left) meridional velocity $\left(\mathrm{m} \mathrm{s}^{-1}\right)$ and (right) relative vorticity normalized by the Coriolis parameter, during an ACME formation. Isopycnal layers $\left(26.5,26.6\right.$, and $26.8 \mathrm{~kg} \mathrm{~m}^{-3}$ ) are contoured as black dashed lines, and the full black line indicates the $0.1 \times 10^{-13} \mathrm{~s}^{-4}$ potential vorticity $(f \mathrm{PV})$.

structure of similar polarity, causing the ACE to intensify and increasing its size (Fig. 10f). On 19 July of year 2, the positive vorticity developed between the ACE that has moved slightly offshore and the anticyclonic vortex present at $17.6^{\circ} \mathrm{N}, 16.7^{\circ} \mathrm{W}$, is detected as a CE (Fig. 10g). Ten days later, both the ACE and CE propagate westward as dipoles, and the coastally bound anticyclonic vortex is squeezed toward the slope and propagates downstream with the boundary current (Fig. 10h). 

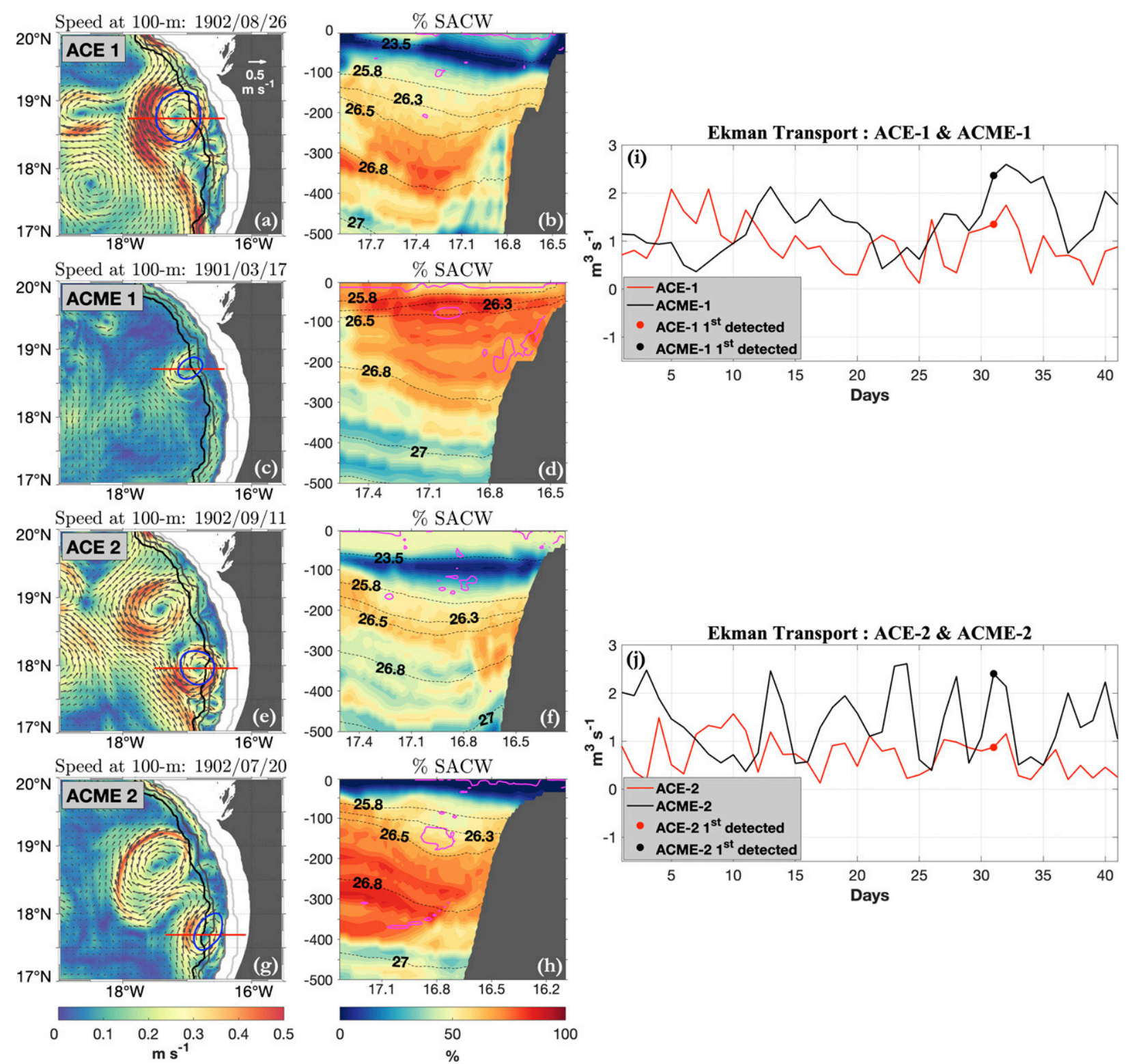

FIG. 9. (left) Snapshots of current speed overlaid with current direction (vectors) and (center) vertical distribution of \% SACW along red zonal transects in the left panels. The shapes of the specific eddies are delineated by the blue circle for (a) ACE-1, (c) ACME-1, (e) ACE-2, and (g) ACME-2, and the magenta contours in (b), (d), (f), and (h) indicate the $0.1 \times 10^{-13} \mathrm{~s}^{-4}$ potential vorticity (fPV). (right) The cross-shore Ekman transport time series across a box englobing the specific eddy shape at the first eddy detection date, with the red (black) dot indicating the first eddy detection date for ACE (ACME).

An analysis of the HRS and $P_{e} K_{e}$ is performed to identify the sources of eddy kinetic energy involved in the generation of the two CEs. If the variables of Eqs. (2) and (4) are written as $A=\bar{A}+A^{\prime}$, in this context, $\bar{A}$ is the temporal mean of the variable over the period of $\mathrm{CE}$ formation (10-day running mean centered at $t=1$ ), whereas $A^{\prime}$ is the fluctuation with respect to that temporal mean. For both CEs, the most relevant term toward eddy kinetic energy is the $P_{e} K_{e}$ (Figs. 11c,f), suggesting that the baroclinic pathway constitutes the major energy source of EKE toward CE genesis. The two energy terms are more significant in boreal summer because of instabilities led from a stronger poleward boundary flow.

At the location of the first CE genesis, a dipole of positive $P_{e} K_{e}$ and negative $P_{e} K_{e}$ that occurred north and south of the CE, respectively, energizing the $\mathrm{CE}$ until it propagates offshore following an elongated positive $P_{e} K_{e}$ patch (Fig. 11c). Generally, both routes of energy transfer, from EPE to EKE (indicated by $P_{e} K_{e}$ ) and MKE to EKE (indicated by HRS) play a role in the generation of the second CE, although the magnitude of $P_{e} K_{e}$ is more important. A dipole of HRS is visible north and south of 

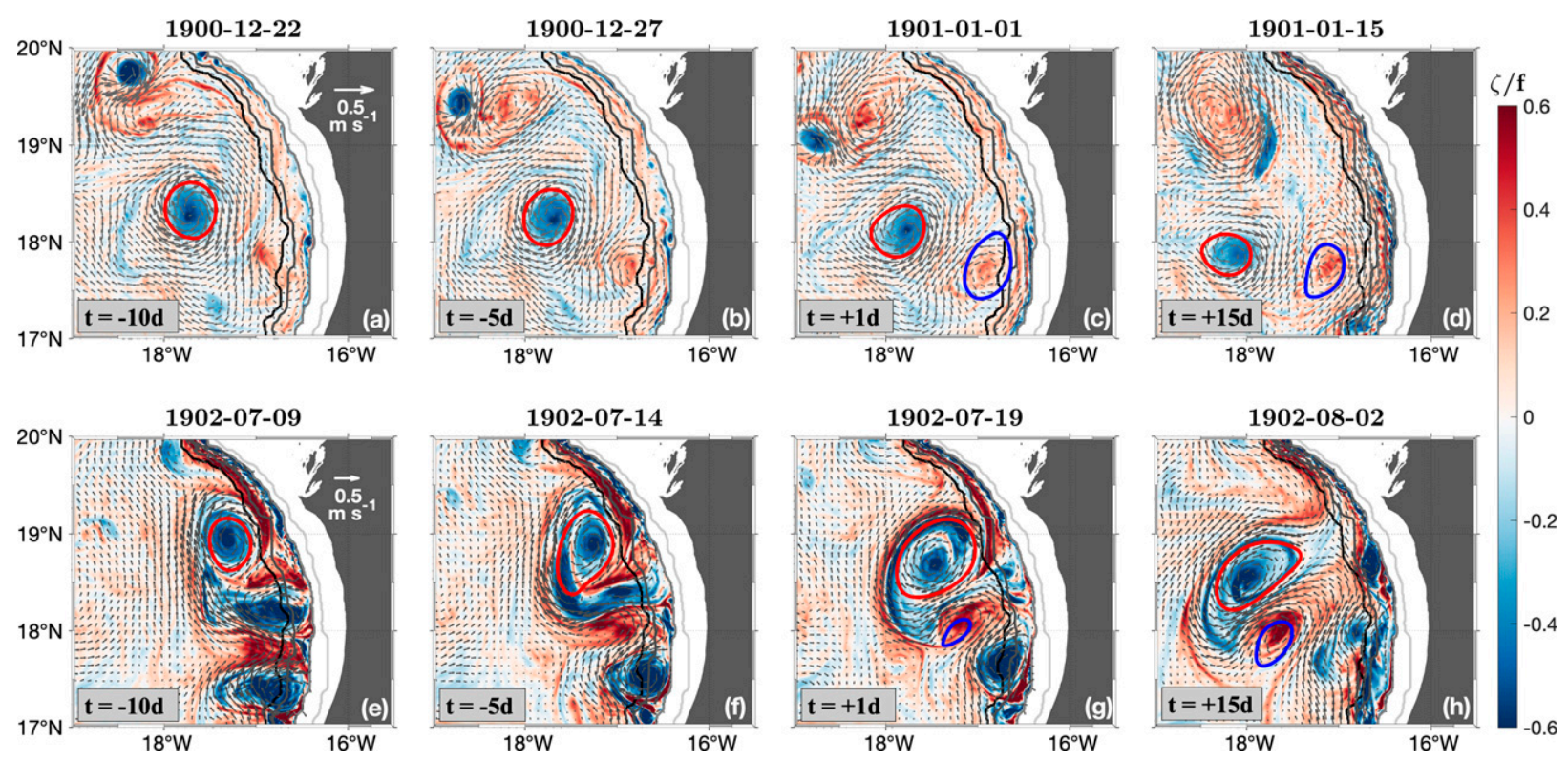

FIG. 10. Time sequence of relative vorticity (normalized by Coriolis parameter) at $100 \mathrm{~m}$ deep of two cyclonic eddies, with the overlaid vectors showing velocities at similar depth. The first detection date of the eddies is at $t=+1$ day. The shape of the cyclonic (anticyclonic) eddies are delineated by the blue (red) circular line. The light gray to black contours show the 50-, 100-, 500-, and 1000-m isobaths.

the identified ACE (Fig. 11e), associated with the shear of the ACE currents. In terms of $P_{e} K_{e}$, positive (negative) flux occurs north (south) of the $\mathrm{CE}$, linked to the large horizontal density gradients with the southwestward flow of the ACE and the northeastward flow of the negative vorticity structure observed upstream (Fig. 10g). Intermittent positive $P_{e} K_{e}$ is also present along the slope in Fig. 11c $\left(16.5^{\circ}-18^{\circ} \mathrm{N}\right)$ and Fig. $11 \mathrm{f}$ $\left(17.1^{\circ}-17.4^{\circ} \mathrm{N}\right)$. These can be associated with submesoscale baroclinic instability, which develops in weakly stratified layers over sloping topography, generated by the Ekman adjustment of the boundary current on the slope (Wenegrat et al. 2018; Contreras et al. 2019). To summarize, in some specific cases, the instabilities caused by the presence of anticyclonic vorticity structures and the Mauritania Current-topography interactions lead to positive vorticity generation, which can develop into cyclonic eddies sourcing their energy from eddy available potential energy. From this proposed mechanism, a delay is expected in CE formation in relative to ACE/ACME formation, which could explain the wintertime peak observed in CE generation (Fig. 4f).

\section{Summary and conclusions}

This study contributes to a comprehensive analysis of the generation mechanisms of cyclonic (CE), anticyclonic (ACE), and anticyclonic mode water (ACME) eddies in the Mauritanian upwelling region, based on the data from a high-resolution ocean general circulation model. An eddy tracking algorithm was applied to the model outputs to identify cyclonic and anticyclonic eddies. Advanced classification pigeonholes anticyclonic eddies further into ACMEs and ACEs through a novel approach that links ACME to high SACW content in addition to low PV water mass observed in their cores. It is found that the model reproduces quite well the complex coastal flow structures and the thermohaline vertical structures of the three simulated eddy types when compared to earlier studies based on observational data (Schütte et al. 2016a). Hotspots with enhanced eddy activity during boreal summer and close to the coast is where ACMEs and ACEs are generated, in agreement with observations (Chaigneau et al. 2009; Schütte et al. 2016a). This led to a confirmation of the importance of coastal processes, in particular the intensifying poleward Mauritania Current, in terms of their effect on drivers of anticyclonic eddy genesis.

Analysis of the energy pathways toward eddy kinetic energy indicates that the Mauritania Current is baroclinically unstable along the coast in boreal summer, especially downstream of critical topographic curvatures. These results are analogous to respective findings in the California Current System (Capet et al. 2008; Marchesiello et al. 2003; Molemaker et al. 2015) and the Peru-Chile Current System (Leth and Shaffer 2001; Colas et al. 2013), where energetic mesoscale eddy generation has been associated with baroclinic instabilities during the intensification of alongshore currents.

The bottom boundary layer has been shown to be a source region of water mass characteristics in the cores of ACMEs. The interaction of an intensifying Mauritania Current with the slope generates a narrow strip of highly negative vertical vorticity on the bottom boundary layer, with low PV waters. This low PV signature arises from the negative vorticity strip and a reduction of the stratification. Following separation of the boundary current from the slope, the eddy core began to move as the anticyclonic vorticity and low PV waters are transported offshore. The coalescence 

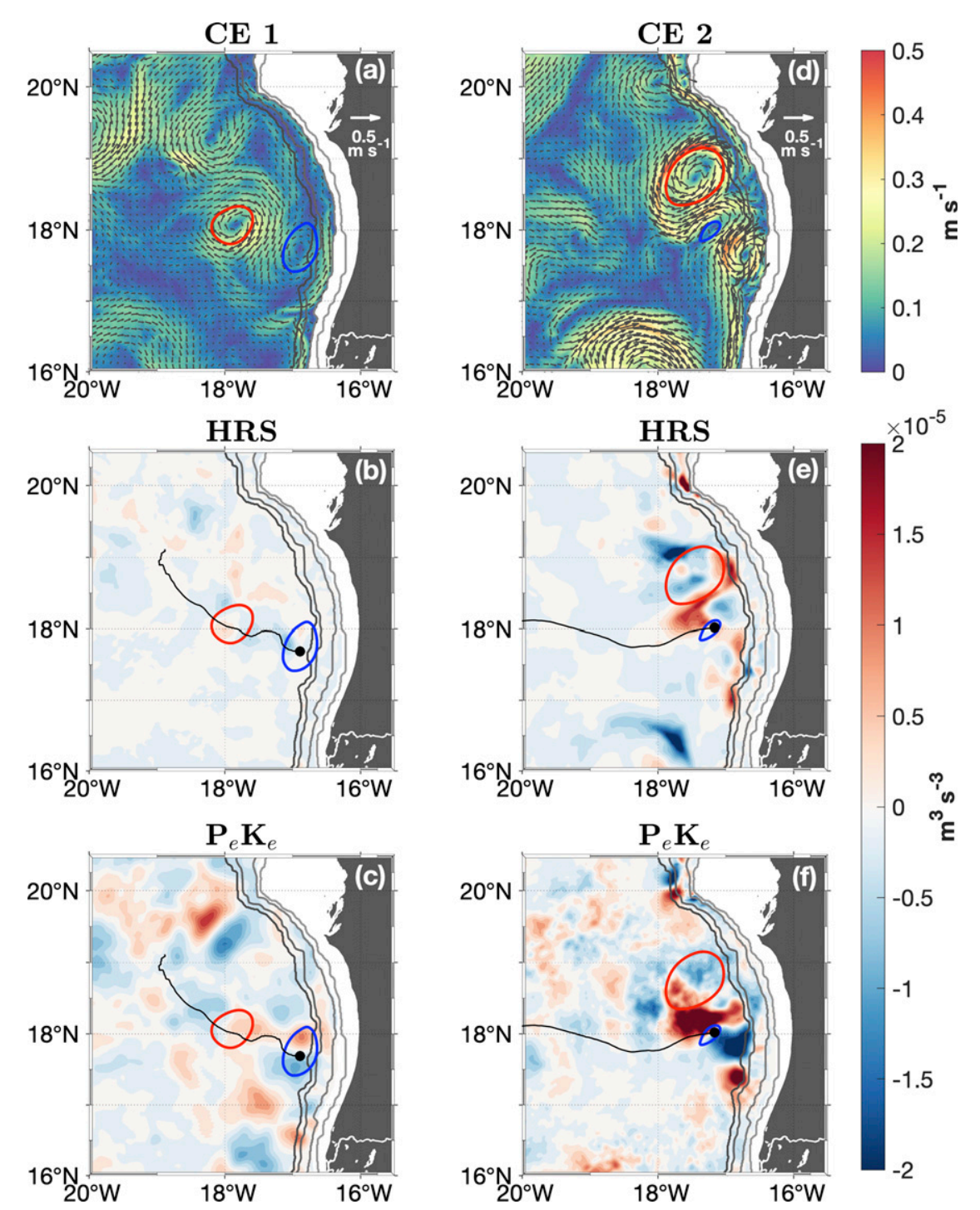

FIG. 11. (a),(d) The current speed at $100 \mathrm{~m}$ deep, overlaid with velocities at similar depth as vectors, with the cyclonic and anticyclonic eddy delineated by the black and red circular lines, respectively. The (b),(e) HRS and (c),(f) $P_{e} K_{e}$ energy terms are integrated over the 50-300-m depth range and averaged over a \pm 10 days from the first eddy detection date. The black lines indicate the propagation pathway of the cyclonic eddies. HRS and $P_{e} K_{e}$ have been smoothed using a $10-\mathrm{km}$ convolution low-pass filter.

of submesoscale structures formed owing to the unstable Mauritania Current results in an increase of the eddy size, which propagate offshore as a coherent structure with an isolated low PV core. This result is in agreement with the classical theory of subsurface eddy formation due to flow separation at topographic curvatures (D'Asaro 1988), and converge to similar processes observed in subsurface eddy generation in other EBUS (Molemaker et al. 2015; Thomsen et al. 2016; Contreras et al. 2019).

During an ACME formation, the water mass characteristic of the genesis area exhibits higher SACW content compared to when an ACE is generated. Our analysis revealed that the coastal upwelling of subsurface SACW, coinciding with anticyclonic vorticity structure generation, can be the determining factor for the structure to develop into either an ACME or an ACE. A reduction of offshore Ekman transport prior to an ACE formation, will inhibit upwelling of higher density water masses typical of SACW closer to the continental slope where the mean flow and topography interact. Therefore, the ACE structure, composed of a lighter water mass, will stay close to or within the surface layers while propagating away from the coast. The ACE will be exposed to surface buoyancy forcing, eventually altering the stratification and PV of the eddy. On the other hand, enhanced offshore Ekman transport will lead to higher SACW content to be trapped in anticyclonic structures. This structure of a relatively dense core 
is characteristic for an ACME and will subduct while propagating offshore and will be shielded from surface buoyancy fluxes. Alternatively, water mass of higher SACW can potentially also be advected into the region, through horizontal advection, prior to eddy formation.

In the model, the interaction between the rotational flow of an anticyclonic vortex offshore, and the poleward Mauritania Current gives rise to positive vorticity and fueled by baroclinic instabilities as main source of energy leads to the generation of simulated coastal cyclonic eddies. This energy source acts to equilibrate the boundary currents and pycnocline tilt (Marchesiello et al. 2003). Other dynamical processes that can also induce shedding of cyclonic eddies in the region include the wind shear due to orographic features (Cardoso et al. 2018), and flow separation of a coastal equatorward current due to intensification of the trade winds (Alpers et al. 2013). Variability in the Mauritania Current is also linked to remote equatorial forcing through intraseasonal coastal trapped waves (CTWs; Klenz et al. 2018). CTWs can intensify the Mauritania Current on a short time scale ( $\sim 7$ days; Klenz et al. 2018), and hence play a role in the temporal variability of eddy formation. This process requires further analysis and is beyond the scope of the present research.

In summary, our study provides insight into the physical drivers of eddy genesis along the Mauritanian coast, highlighting the important role of local upwelling, the baroclinicity of the system as well as the mean flow-topographic interactions in the shedding of cyclonic, anticyclonic, and anticyclonic mode water eddies. We emphasize that although our analysis is based on a rather short model (two years), conditions in the thermocline are close to observations, but on the other hand, this limits the significance of our eddy statistics. The ACMEs can have a lifetime longer than one year (Karstensen et al. 2015) and trap water masses typical of continental shelves, transporting them in the open ocean. Hence it is critical in further understanding the cross-shore eddy-induced transport of coastal biogeochemical properties. A proper representation of ACMEs, maybe through the formation mechanisms discussed here, are also crucial since they contribute to the creation of an upper, shallow oxygen minimum (Schütte et al. 2016b) that is located above the main OMZ (Karstensen et al. 2008).

Acknowledgments. The authors appreciate support from the Deutsche Forschungsgemeinschaft as part of the Sonderforschungsbereich 754 "Climate-Biogeochemistry Interactions in the Tropical Ocean" (www.sfb754.de) and the Deutsche Bundesministerium für Bildung und Forschung (BMBF) project REEBUS. This research was also undertaken thanks in parts to research funding provided by the Ocean Frontier Institute, through an award from the Canada First Research Excellence Fund. KF also acknowledges support by the NSERC Discovery program. We are grateful to $\mathrm{T}$. Klenz for providing the processed hydrographic data. The authors would like to thank the two anonymous reviewers for comments and suggestions that greatly improved this manuscript.
Data availability statement. The AVISO data are available from the Copernicus Marine and Environment Monitoring Service (CMEMS; http://marine.copernicus.eu); and the sea surface temperature from the Remote Sensing Systems website (http://www.remss.com). The model configuration is available upon request. Introductory visualizations of a choice of model output are achieved at https://doi.org/10.5281/zenodo.4518783.

\section{REFERENCES}

Alpers, W., and Coauthors, 2013: A small-scale oceanic eddy off the coast of West Africa studied by multi-sensor satellite and surface drifter data. Remote Sens. Environ., 129, 132-143, https://doi.org/10.1016/j.rse.2012.10.032.

Altabet, M. A., and Coauthors, 2012: An eddy-stimulated hotspot for fixed nitrogen-loss from the Peru oxygen minimum zone. Biogeosciences, 9, 4897-4908, https://doi.org/10.5194/bg-94897-2012.

Amores, A., G. Jordà, T. Arsouze, and J. Le Sommer, 2018: Up to what extent can we characterize ocean eddies using present-day gridded altimetric products? J. Geophys. Res. Oceans, 123, 7220-7236, https://doi.org/10.1029/2018JC014140.

Amos, C. M., R. M. Castelao, and P. M. Medeiros, 2019: Offshore transport of particulate organic carbon in the California Current System by mesoscale eddies. Nat. Commun., 10, 4940, https://doi.org/10.1038/s41467-019-12783-5.

Antonov, J. I., and Coauthors, 2010: Salinity. Vol. 2, World Ocean Atlas 2009, NOAA Atlas NESDIS 69, 184 pp.

Arévalo-Martínez, D. L., A. Kock, C. R. Löscher, R. A. Schmitz, L. Stramma, and H. W. Bange, 2016: Influence of mesoscale eddies on the distribution of nitrous oxide in the eastern tropical South Pacific. Biogeosciences, 13, 1105-1118, https:// doi.org/10.5194/bg-13-1105-2016.

Armi, L., and W. Zenk, 1984: Large lenses of highly saline Mediterranean water. J. Phys. Oceanogr., 14, 1560-1576, https:// doi.org/10.1175/1520-0485(1984)014<1560:LLOHSM>2.0. $\mathrm{CO} ; 2$.

Bakun, A., 1973: Coastal upwelling indices, west coast of North America, 1946-71. NOAA Tech. Rep. NMFS SSRF-671, 103 pp., https://spo.nmfs.noaa.gov/sites/default/files/legacypdfs/SSRF671.pdf.

- 1975: Daily and weekly upwelling indices, west coast of North America, 1967-73. NOAA Tech. Rep. NMFS SSRF693, 114 pp., https://spo.nmfs.noaa.gov/sites/default/files/legacypdfs/SSRF693.pdf.

Barceló-Llull, B., and Coauthors, 2017: Anatomy of a subtropical intrathermocline eddy. Deep-Sea Res. I, 124, 126-139, https:// doi.org/10.1016/j.dsr.2017.03.012.

Bashmachnikov, I., F. Neves, T. Calheiros, and X. Carton, 2015: Properties and pathways of Mediterranean water eddies in the Atlantic. Prog. Oceanogr., 137, 149-172, https://doi.org/ 10.1016/j.pocean.2015.06.001.

Benthuysen, J., and L. N. Thomas, 2012: Friction and diapycnal mixing at a slope: Boundary control of potential vorticity. $J$. Phys. Oceanogr., 42, 1509-1523, https://doi.org/10.1175/JPOD-11-0130.1.

Brandt, P., and Coauthors, 2015: On the role of circulation and mixing in the ventilation of oxygen minimum zones with a focus on the eastern tropical North Atlantic. Biogeosciences, 12, 489-512, https://doi.org/10.5194/bg-12-489-2015. 
Capet, X. J., P. Marchesiello, and J. C. McWilliams, 2004: Upwelling response to coastal wind profiles. Geophys. Res. Lett., 31, L13311, https://doi.org/10.1029/2004GL020123.

— J. C. McWilliams, M. J. Molemaker, and A. F. Shchepetkin, 2008: Mesoscale to submesoscale transition in the California Current System. Part I: Flow structure, eddy flux, and observational tests. J. Phys. Oceanogr., 38, 29-43, https://doi.org/10. 1175/2007JPO3671.1.

Cardoso, C., R. M. A. Caldeira, A. Stegner, and P. Relvas, 2018: Islands as eddy transformation and generation hotspots: Cape Verde case study. Prog. Oceanogr., 184, 102271, https:// doi.org/10.1016/j.pocean.2020.102271.

Carton, X., N. Daniault, J. Alves, L. Cherubin, and I. Ambar, 2010: Meddy dynamics and interaction with neighboring eddies southwest of Portugal: Observations and modeling. J. Geophys. Res., 115, C06017, https://doi.org/10.1029/2009JC005646.

Chaigneau, A., G. Eldin, and B. Dewitte, 2009: Eddy activity in the four major upwelling systems from satellite altimetry (1992-2007). Prog. Oceanogr., 83, 117-123, https://doi.org/10. 1016/j.pocean.2009.07.012.

—, M. Le Texier, G. Eldin, C. Grados, and O. Pizarro, 2011: Vertical structure of mesoscale eddies in the eastern South Pacific Ocean: A composite analysis from altimetry and Argo profiling floats. J. Geophys. Res., 116, C11025, https://oi.org/ 10.1029/2011JC007134.

— , and Coauthors, 2013: Near-coastal circulation in the Northern Humboldt Current System from shipboard ADCP data. J. Geophys. Res. Oceans, 118, 5251-5266, https://doi.org/10. 1002/jgrc.20328.

Chelton, D. B., M. G. Schlax, R. M. Samelson, and R. A. de Szoeke, 2007: Global observations of large oceanic eddies. Geophys. Res. Lett., 34, L15606, https://doi.org/10.1029/ 2007GL030812.

—, Gaube, P., Schlax, M. G., Early, J. J., and Samelson, R. M., 2011a: The influence of nonlinear mesoscale eddies on nearsurface oceanic chlorophyll. Science. 334, 328-332, https://doi. org/10.1126/science.1208897.

— , M. G. Schlax, and R. M. Samelson, 2011b: Global observations of nonlinear mesoscale eddies. Prog. Oceanogr., 91, 167-216, https://doi.org/10.1016/j.pocean.2011.01.002.

Christiansen, S., and Coauthors, 2018: Particulate matter flux interception in oceanic mesoscale eddies by the polychaete Poeobius sp. Limnol. Oceanogr., 63, 2093-2109, https://doi. org/10.1002/lno.10926.

Colas, F., X. Capet, J. C. McWilliams, and Z. Li, 2013: Mesoscale eddy buoyancy flux and eddy-induced circulation in eastern boundary currents. J. Phys. Oceanogr., 43, 1073-1095, https:// doi.org/10.1175/JPO-D-11-0241.1.

Combes, V., F. Chenillat, and E. Di Lorenzo, 2013: Cross-shore transport variability in the California Current: Ekman upwelling vs. eddy dynamics. Prog. Oceanogr., 109, 78-89, https:// doi.org/10.1016/j.pocean.2012.10.001.

Contreras, M., O. Pizarro, B. Dewitte, H. H. Sepulveda, and L. Renault, 2019: Subsurface mesoscale eddy generation in the ocean off central Chile. J. Geophys. Res. Oceans, 124, 57005722, https://doi.org/10.1029/2018JC014723.

Cushman-Roisin, B., and B. Tang, 1990: Geostrophic turbulence and emergence of eddies beyond the radius of deformation. J. Phys. Oceanogr., 20, 97-113, https://doi.org/10.1175/15200485(1990)020<0097:GTAEOE > 2.0.CO;2.

D'Asaro, E. A., 1988: Generation of submesoscale vortices: A new mechanism. J. Geophys. Res., 93, 6685-6693, https://doi. org/10.1029/JC093iC06p06685. de Marez, C., and Coauthors, 2020: Oceanic vortex mergers are not isolated but influenced by the $\beta$-effect and surrounding eddies. Sci. Rep., 10, 2897, https://doi.org/10.1038/s41598-02059800-y.

Dietze, H., U. Löptien, and J. Getzlaff, 2020: MOMSO 1.0 - An eddying Southern Ocean model configuration with fairly equilibrated natural carbon. Geosci. Model Dev., 13, 71-97, https://doi.org/10.5194/gmd-13-71-2020.

Dilmahamod, A. F., and Coauthors, 2018: SIDDIES corridor: A major east-west pathway of long-lived surface and subsurface eddies crossing the subtropical South Indian Ocean. J. Geophys. Res. Oceans, 123, 5406-5425, https://doi.org/10.1029/ 2018JC013828.

Dong, C., J. C. McWilliams, Y. Liu, and D. Chen, 2014: Global heat and salt transports by eddy movement. Nat. Commun., 5, 3294, https://doi.org/10.1038/ncomms4294.

Ducet, N., P. Y. Le Traon, and G. Reverdin, 2000: Global highresolution mapping of ocean circulation from TOPEX/Poseidon and ERS-1 and -2. J. Geophys. Res., 105, 192477-192498, https://doi.org/10.1029/2000JC900063.

Ellwood, M. J., R. F. Strzepek, P. G. Strutton, T. W. Trull, M. Fourquez, and P. W. Boyd, 2020: Distinct iron cycling in a Southern Ocean eddy. Nat. Commun., 11, 825, https://doi.org/ 10.1038/s41467-020-14464-0.

Fiedler, B., and Coauthors, 2016: Oxygen utilization and downward carbon flux in an oxygen-depleted eddy in the eastern tropical North Atlantic. Biogeosciences, 13, 5633-5647, https://doi.org/10.5194/bg-13-5633-2016.

Fischer, T., and Coauthors, 2013: Diapycnal oxygen supply to the tropical North Atlantic oxygen minimum zone. Biogeosciences, 10, 5079-5093, https://doi.org/10.5194/bg-10-5079-2013.

Frenger, I., and Coauthors, 2018: Biogeochemical role of subsurface coherent eddies in the ocean: Tracer cannonballs, hypoxic storms, and microbial stewpots? Global Biogeochem. Cycles, 32, 226-249, https://doi.org/10.1002/2017GB005743.

Garfield, N., C. A. Collins, R. G. Paquette, and E. Carter, 1999: Lagrangian exploration of the California Undercurrent, 1992-95. J. Phys. Oceanogr., 29, 560-583, https://doi.org/10. 1175/1520-0485(1999)029<0560:LEOTCU>2.0.CO;2.

Glessmer, M. S., C. Eden, and A. Oschlies, 2009: Contribution of oxygen minimum zone waters to the coastal upwelling off Mauritania. Prog. Oceanogr., 83, 143-150, https://doi.org/10. 1016/j.pocean.2009.07.015.

Griffies, S. M., and R. W. Hallberg, 2000: Biharmonic friction with a Smagorinsky-Like viscosity for use in large-scale eddypermitting ocean models. Mon. Wea. Rev., 128, 2935-2946, https://doi.org/10.1175/1520-0493(2000)128<2935:BFWASL > 2.0.CO;2.

, and Coauthors, 2009: Coordinated Ocean-ice Reference Experiments (COREs). Ocean Modell., 26, 1-46, https://doi. org/10.1016/j.ocemod.2008.08.007.

Gruber, N., and Coauthors, 2011: Eddy-induced reduction of biological production in eastern boundary upwelling systems. Nat. Geosci., 4, 787-792, https://doi.org/10.1038/ngeo1273.

Grundle, D. S., and Coauthors, 2017: Low oxygen eddies in the eastern tropical North Atlantic: Implications for $\mathrm{N}_{2} \mathrm{O}$ cycling. Sci. Rep., 7, 4806, https://doi.org/10.1038/s41598-017-04745-y.

Gula, J., M. J. Molemaker, and J. C. McWilliams, 2015: Gulf stream dynamics along the southeastern U.S. seaboard. $J$. Phys. Oceanogr., 45, 690-715, https://doi.org/10.1175/JPO-D14-0154.1.

Hahn, J., P. Brandt, R. J. Greatbatch, G. Krahmann, and A. Körtzinger, 2014: Oxygen variance and meridional oxygen 
supply in the tropical north east Atlantic oxygen minimum zone. Climate Dyn., 43, 2999-3024, https://doi.org/10.1007/ s00382-014-2065-0.

Hebert, D., N. Oakey, and B. Ruddick, 1990: Evolution of a Mediterranean salt lens: Scalar properties. J. Phys. Oceanogr., 20, 1468-1483, https://doi.org/10.1175/1520-0485(1990)020<1468: EOAMSL $>2.0 . \mathrm{CO} ; 2$.

Holte, J., F. Straneo, C. Moffat, R. Weller, and J. T. Farrar, 2013: Structure and surface properties of eddies in the southeast Pacific Ocean. J. Geophys. Res. Oceans, 118, 2295-2309, https://doi.org/10.1002/jgrc.20175.

Hormazabal, S., V. Combes, C. E. Morales, M. A. CorreaRamirez, E. Di Lorenzo, and S. Nuñez, 2013: Intrathermocline eddies in the coastal transition zone off central Chile (31-41요. J. Geophys. Res. Oceans, 118, 4811-4821, https:// doi.org/10.1002/jgrc.20337.

Hoskins, B. J., 1974: The role of potential vorticity in symmetric stability and instability. Quart. J. Roy. Meteor. Soc., 100, 480482, https://doi.org/10.1002/qj.49710042520.

Johns, W. E., R. J. Zantopp, and G. J. Goni, 2003: Cross-Gyre Transport by North Brazil Current Rings. Elsevier Oceanography Series, Vol. 68, Elsevier, 411-441, https://doi.org/10. 1016/S0422-9894(03)80156-3.

Jones, P., and A. Folkard, 1970: Chemical oceanographical observations off the coast of North-West Africa, with special reference to the process of upwelling. Rapp. P.-V. Reun. Cons. Int. Explor. Mer, 159, 38-60.

Karstensen, J., L. Stramma, and M. Visbeck, 2008: Oxygen minimum zones in the eastern tropical Atlantic and Pacific oceans. Prog. Oceanogr., 77, 331-350, https://doi.org/10.1016/j. pocean.2007.05.009.

— North Atlantic Ocean. Biogeosciences, 12, 2597-2605, https:// doi.org/10.5194/bg-12-2597-2015.

— , and Coauthors, 2017: Upwelling and isolation in oxygendepleted anticyclonic modewater eddies and implications for nitrate cycling. Biogeosciences, 14, 2167-2181, https://doi.org/ 10.5194/bg-14-2167-2017.

Klenz, T., M. Dengler, and P. Brandt, 2018: Seasonal variability of the Mauritania Current and hydrography at $18^{\circ} \mathrm{N}$. J. Geophys. Res. Oceans, 123, 8122-8137. https://doi.org/10.1029/ 2018JC014264.

Kurian, J., F. Colas, X. Capet, J. C. McWilliams, and D. B. Chelton, 2011: Eddy properties in the California Current System. J. Geophys. Res., 116, C08027, https://doi.org/10.1029/ 2010JC006895.

Large, W. G., and S. G. Yeager, 2004: Diurnal to decadal global forcing for ocean and sea-ice models: The data sets and flux climatologies. NCAR Tech. Note NCAR/TN-460+ST, 105 pp., https://doi.org/10.5065/D6KK98Q6.

— , and — 2009: The global climatology of an interannually varying air-sea flux data set. Climate Dyn., 33, 341-364, https://doi.org/10.1007/s00382-008-0441-3.

—, J. C. McWilliams, and S. C. Doney, 1994: Oceanic vertical mixing: A review and a model with a nonlocal boundary layer parameterization. Rev. Geophys., 32, 363-403, https:// doi.org/10.1029/94RG01872.

Laxenaire, R., S. Speich, B. Blanke, A. Chaigneau, C. Pegliasco, and A. Stegner, 2018: Anticyclonic eddies connecting the western boundaries of Indian and Atlantic Oceans. J. Geophys. Res. Oceans, 123, 7651-7677, https://doi.org/10.1029/ 2018JC014270.
Lázaro, C., M. J. Fernandes, A. M. P. Santos, and P. Oliveira, 2005: Seasonal and interannual variability of surface circulation in the Cape Verde region from 8 years of merged T/P and ERS-2 altimeter data. Remote Sens. Environ., 98, 45-62, https://doi.org/10.1016/j.rse.2005.06.005.

Leth, O., and G. Shaffer, 2001: A numerical study of the seasonal variability in the circulation off central Chile. J. Geophys. Res., 106, 22 229-22 248, https://doi.org/10.1029/2000JC000627.

Le Vu, B., A. Stegner, and T. Arsouze, 2018: Angular momentum eddy detection and tracking algorithm (AMEDA) and its application to coastal eddy formation. J. Atmos. Oceanic Technol., 35, 739-762, https://doi.org/10.1175/JTECH-D-170010.1.

Lévy, M., R. Ferrari, P. J. S. Franks, A. P. Martin, and P. Rivière, 2012: Bringing physics to life at the submesoscale. Geophys. Res. Lett., 39, L14602, https://doi.org/10.1029/2012GL052756.

Li, C., Z. Zhang, W. Zhao, and J. Tian, 2017: A statistical study on the subthermocline submesoscale eddies in the northwestern Pacific Ocean based on Argo data. J. Geophys. Res. Oceans, 122, 3586-3598, https://doi.org/10.1002/2016JC012561.

Liang, J. H., J. C. McWilliams, J. Kurian, F. Colas, P. Wang, and Y. Uchiyama, 2012: Mesoscale variability in the northeastern tropical Pacific: Forcing mechanisms and eddy properties. J. Geophys. Res., 117, C07003, https://doi.org/10.1029/2012JC008008.

Locarnini, R. A., A. V. Mishonov, J. I. Antonov, T. P. Boyer, H. E. Garcia, O. K. Baranova, M. M. Zweng, and D. R. Johnson, 2010: Temperature. Vol. 1, World Ocean Atlas 2009, NOAA Atlas NESDIS 68, $184 \mathrm{pp}$.

Löscher, C. R., and Coauthors, 2015: Hidden biosphere in an oxygen-deficient Atlantic open-ocean eddy: Future implications of ocean deoxygenation on primary production in the eastern tropical North Atlantic. Biogeosciences, 12, 7467-7482, https://doi.org/10.5194/bg-12-7467-2015.

Lukas, R., and F. Santiago-Mandujano, 2001: Extreme water mass anomaly observed in the Hawaii ocean time-series. Geophys. Res. Lett., 28, 2931-2934, https://doi.org/10.1029/ 2001 GL013099.

Marchesiello, P., J. C. McWilliams, and A. Shchepetkin, 2003: Equilibrium structure and dynamics of the California Current System. J. Phys. Oceanogr., 33, 753-783, https://doi.org/10. 1175/1520-0485(2003)33<753:ESADOT>2.0.CO;2.

Marshall, D. P., and C. E. Tansley, 2001: An implicit formula for boundary current separation. J. Phys. Oceanogr., 31, 1633-1638, https://doi.org/10.1175/1520-0485(2001)031<1633:AIFFBC> 2.0.CO;2.

McCoy, D., D. Bianchi, and A. L. Stewart, 2020: Global observations of submesoscale coherent vortices in the ocean. Prog. Oceanogr., 189, 102452, https://doi.org/10.1016/j.pocean.2020. 102452.

McCreary, J. P., P. K. Kundu, and S.-Y. Chao, 1987: On the dynamics of the California Current System. J. Mar. Res., 45, 1-32, https://doi.org/10.1357/002224087788400945.

McGillicuddy, D. J., and Coauthors, 2007: Eddy/wind interactions stimulate extraordinary mid-ocean plankton blooms. Science, 316, 1021-1026, https://doi.org/10.1126/science.1136256.

McWilliams, J. C., 1985: Submesoscale coherent vortices in the ocean. Rev. Geophys., 23, 165-182, https://doi.org/10.1029/ RG023i002p00165.

— yses of MODE array data. Deep-Sea Res. Oceanogr. Abstr., 23, 285-300, https://doi.org/10.1016/0011-7471(76)90871-8.

Mittelstaedt, E., 1983: The upwelling area off northwest AfricaA description of phenomena related to coastal upwelling. 
Prog. Oceanogr., 12, 307-331, https://doi.org/10.1016/00796611(83)90012-5.

- 1991: The ocean boundary along the northwest African coast: Circulation and oceanographic properties at the sea surface. Prog. Oceanogr., 26, 307-355, https://doi.org/10.1016/ 0079-6611(91)90011-A.

Mkhinini, N., A. L. S. Coimbra, A. Stegner, T. Arsouze, I. Taupier-Letage, and K. Béranger, 2014: Long-lived mesoscale eddies in the eastern Mediterranean Sea: Analysis of 20 years of AVISO geostrophic velocities. J. Geophys. Res. Oceans, 119, 8603-8626, https://doi.org/10.1002/2014JC010176.

Molemaker, M. J., J. C. McWilliams, and W. K. Dewar, 2015: Submesoscale instability and generation of mesoscale anticyclones near a separation of the California Undercurrent. $J$. Phys. Oceanogr., 45, 613-629, https://doi.org/10.1175/JPO-D13-0225.1.

Munk, W. H., 1950: On the wind-driven ocean circulation. $J$. Meteor., 7, 80-93, https://doi.org/10.1175/1520-0469(1950)007< 0080:OTWDOC $>2.0 . \mathrm{CO} ; 2$.

Nauw, J. J., H. M. van Aken, J. R. E. Lutjeharms, and W. P. M. de Ruijter, 2006: Intrathermocline eddies in the southern Indian Ocean. J. Geophys. Res., 111, C03006, https://oi.org/ 10.1029/2005JC002917.

Pantoja, D., S. Marinone, A. Parés-Sierra, and F. Gómez-Valdivia, 2012: Numerical modeling of seasonal and mesoscale hydrography and circulation in the Mexican central Pacific. Cienc. Mar., 38, 363-379, https://doi.org/10.7773/cm.v38i2.2007.

Pares-Sierra, A., W. B. White, and C. Tai, 1993: Wind-driven coastal generation of annual mesoscale eddy activity in the California Current. J. Phys. Oceanogr., 23, 1110-1121, https://doi.org/10.1175/1520-0485(1993)023<1110:WDCGOA> 2.0.CO;2.

Pastor, M. V., J. L. Pelegrí, A. Hernández-Guerra, J. Font, J. Salat, and M. Emelianov, 2008: Water and nutrient fluxes off northwest Africa. Cont. Shelf Res., 28, 915-936, https://doi. org/10.1016/j.csr.2008.01.011.

Pelland, N. A., C. C. Eriksen, and C. M. Lee, 2013: Subthermocline eddies over the Washington continental slope as observed by Seagliders, 2003-09. J. Phys. Oceanogr., 43, 2025-2053, https://doi.org/10.1175/JPO-D-12-086.1.

Peña-Izquierdo, J., and Coauthors, 2015: Water mass pathways to the North Atlantic oxygen minimum zone. J. Geophys. Res. Oceans, 120, 3350-3372, https://doi.org/10.1002/2014JC010557.

Polo, I., A. Lazar, B. Rodriguez-Fonseca, and S. Arnault, 2008: Oceanic Kelvin waves and tropical Atlantic intraseasonal variability: 1. Kelvin wave characterization. J. Geophys. Res., 113, C07009, https://doi.org/10.1029/2007JC004495.

Renault, L., C. Deutsch, J. C. McWilliams, H. Frenzel, J. H. Liang, and F. Colas, 2016: Partial decoupling of primary productivity from upwelling in the California Current System. Nat. Geosci., 9, 505-508, https://doi.org/10.1038/ngeo2722.

Røed, L. P., 1980: Curvature effects on hydraulically driven inertial boundary currents. J. Fluid Mech., 96, 395-412, https:// doi.org/10.1017/S0022112080002182.

Schütte, F., and Coauthors, 2016b: Characterization of "deadzone" eddies in the eastern tropical North Atlantic. Biogeosciences, 13, 5865-5881, https://doi.org/10.5194/bg-13-58652016.

— P. Prandt, and J. Karstensen, 2016a: Occurrence and characteristics of mesoscale eddies in the tropical northeastern Atlantic Ocean. Ocean Sci., 12, 663-685, https://doi.org/10. 5194/os-12-663-2016.
Shapiro, R., 1970: Smoothing, filtering, and boundary effects. Rev. Geophys., 8, 359-387, https://doi.org/10.1029/RG008i002p00359.

Smagorinsky, J., 1963: General circulation experiments with the primitive equations. Mon. Wea. Rev., 91, 99-164, https://doi. org/10.1175/1520-0493(1963)091<0099:GCEWTP>2.3.CO;2.

- 1993: Some historical remarks on the use of nonlinear viscosities. Large Eddy Simulation Complex Engineering Geophysical Flows, B. Galperin and S. A. Orszag, Eds., Cambridge University Press, 69-106.

Stramma, L., S. Hüttl, and J. Schafstall, 2005: Water masses and currents in the upper tropical northeast Atlantic off northwest Africa. J. Geophys. Res., 110, C12006, https://doi.org/10. 1029/2005JC002939.

_ G. C. Johnson, E. Firing, and S. Schmidtko, 2010: Eastern Pacific oxygen minimum zones: Supply paths and multidecadal changes. J. Geophys. Res., 115, C09011, https://doi.org/10. 1029/2009JC005976.

Tchipalanga, P., and Coauthors, 2018: Eastern boundary circulation and hydrography off Angola: Building Angolan oceanographic capacities. Bull. Amer. Meteor. Soc., 99, 1589-1605, https://doi.org/10.1175/BAMS-D-17-0197.1.

Tedesco, P., J., Gula, C. Ménesguen, P. Penven, and M. Krug, 2019: Generation of submesoscale frontal eddies in the Agulhas Current. J. Geophys. Res. Oceans, 124, 7606-7625, https:// doi.org/10.1029/2019JC015229.

Thomas, L. N., J. R. Taylor, R. Ferrari, and T. M. Joyce, 2013: Symmetric instability in the Gulf Stream. Deep-Sea Res. II, 91, 96-110, https://doi.org/10.1016/j.dsr2.2013.02.025.

Thomsen, S., T. Kanzow, G. Krahmann, R. J. Greatbatch, M. Dengler, and G. Lavik, 2016: The formation of a subsurface anticyclonic eddy in the Peru-Chile Undercurrent and its impact on the near-coastal salinity, oxygen, and nutrient distributions. J. Geophys. Res. Oceans, 121, 476-501, https://doi. org/10.1002/2015JC010878.

Tomczak, M., 1981: An analysis of mixing in the frontal zone of South and North Atlantic Central Water off North-West Africa. Prog. Oceanogr., 10, 173-192, https://doi.org/10.1016/ 0079-6611(81)90011-2.

Uchida, T., D. P. Balwada, R. A. Abernathey, G. K. McKinley, S. Smith, and M. Lévy, 2020: Vertical eddy iron fluxes support primary production in the open Southern Ocean. Nat. Commun., 11, 1125, https://doi.org/10.1038/s41467-020-14955-0.

Vignudelli, S., A. G. Kostianoy, P. Cipollini, and J. Benveniste, Eds., 2011: Coastal Altimetry. Springer, 578 pp.

Wenegrat, J. O., J. Callies, and L. N. Thomas, 2018: Submesoscale baroclinic instability in the bottom boundary layer. J. Phys. Oceanogr., 48, 2571-2592, https://doi.org/10.1175/JPO-D-170264.1.

Williams, R. G., and V. Roussenov, 2003: The role of sloping sidewalls in forming potential vorticity contrasts in the ocean interior. J. Phys. Oceanogr., 33, 633-648, https://doi.org/10. 1175/1520-0485(2003)33<633:TROSSI > 2.0.CO;2.

Wunsch, C., 1997: The vertical partition of oceanic horizontal kinetic energy. J. Phys. Oceanogr., 27, 1770-1794, https://doi. org/10.1175/1520-0485(1997)027<1770:TVPOOH>2.0.CO;2.

Zamudio, L., H. E. Hurlburt, E. J. Metzger, and C. E. Tilburg, 2007: Tropical wave-induced oceanic eddies at Cabo Corrientes and the María Islands, Mexico. J. Geophys. Res., 112, C05048, https://doi.org/10.1029/2006JC004018.

Zhang, Z., W. Wang, and B. Qiu, 2014: Oceanic mass transport by mesoscale eddies. Science, $\mathbf{3 4 5}, 322-324$, https://doi.org/10. 1126/science. 1252418 . 